Article

\title{
Assessment of Nanopollution from Commercial Products in Water Environments
}

\author{
Raisibe Florence Lehutso ${ }^{1,2} \mathbb{D}$ and Melusi Thwala $1,3,4, * \mathbb{D}$ \\ 1 Water Centre, Council for Scientific and Industrial Research, Pretoria 0001, South Africa; flehutso@csir.co.za \\ 2 Department of Chemical Sciences, University of Johannesburg, Johannesburg 2028, South Africa \\ 3 Department of Environmental Health, Nelson Mandela University, Gqeberha 6019, South Africa \\ 4 Centre for Environmental Management, University of the Free State, Bloemfontein 9031, South Africa \\ * Correspondence: mthwala@csir.co.za
}

check for updates

Citation: Lehutso, R.F.; Thwala, M. Assessment of Nanopollution from Commercial Products in Water Environments . Nanomaterials 2021, 11, 2537. https://doi.org/ 10.3390/nano11102537

Academic Editor: Vivian Hsiu-Chuan Liao

Received: 24 August 2021 Accepted: 18 September 2021 Published: 28 September 2021

Publisher's Note: MDPI stays neutral with regard to jurisdictional claims in published maps and institutional affiliations.

Copyright: (c) 2021 by the authors. Licensee MDPI, Basel, Switzerland. This article is an open access article distributed under the terms and conditions of the Creative Commons Attribution (CC BY) license (https:// creativecommons.org/licenses/by/ $4.0 /)$.

\begin{abstract}
The use of nano-enabled products (NEPs) can release engineered nanomaterials (ENMs) into water resources, and the increasing commercialisation of NEPs raises the environmental exposure potential. The current study investigated the release of ENMs and their characteristics from six commercial products (sunscreens, body creams, sanitiser, and socks) containing $\mathrm{nTiO}_{2}, \mathrm{nAg}$, and $\mathrm{nZnO}$. ENMs were released in aqueous media from all investigated NEPs and were associated with ions $\left(\mathrm{Ag}^{+}\right.$and $\left.\mathrm{Zn}^{2+}\right)$ and coating agents ( $\mathrm{Si}$ and $\mathrm{Al}$ ). NEPs generally released elongated $(7-9 \times 66-70 \mathrm{~nm})$ and angular $(21-80 \times 25-79 \mathrm{~nm}) \mathrm{nTiO}_{2}$, near-spherical $(12-49 \mathrm{~nm})$ and angular $\mathrm{nAg}(21-76 \times 29-77 \mathrm{~nm})$, and angular $\mathrm{nZnO}(32-36 \times 32-40 \mathrm{~nm})$. NEPs released varying ENMs' total concentrations ( $\mathrm{ca} 0.4-95 \%$ ) of total $\mathrm{Ti}, \mathrm{Ag}, \mathrm{Ag}^{+}, \mathrm{Zn}$, and $\mathrm{Zn}^{2+}$ relative to the initial amount of ENMs added in NEPs, influenced by the nature of the product and recipient water quality. The findings confirmed the use of the examined NEPs as sources of nanopollution in water resources, and the physicochemical properties of the nanopollutants were determined. Exposure assessment data from real-life sources are highly valuable for enriching the robust environmental risk assessment of nanotechnology.
\end{abstract}

Keywords: nanopollution; nano-enabled products; engineered nanomaterials; physicochemical properties; aquatic environments

\section{Introduction}

The global commercialisation of nano-enabled products (NEPs) is growing rapidly year on year [1], and it is estimated to grow from USD 39.2 billion in 2016 to over USD 125 billion by 2024 [2]. Approximately 5000 NEPs were identified in various global inventories between 2015 and 2021, belonging to six product categories, namely: health and fitness, electronics and computers, home and garden, appliances, automotive, and food beverages [3-7]. These inventories are generally dominated by health and fitness NEPs, such as sunscreens, personal care products, and clothing products [3-7], which exhibit medium to high probability of emitting engineered nanomaterials (ENMs) into the environment during use, especially water resources (i.e., environmental exposure) $[1,6]$.

Increasing the production and use of NEPs consequently raises the probability of proportional ENMs' release into aquatic environments; therefore, NEPs are potential sources of daily nanopollution [6,8]. For instance, the release of some commonly applied ENMs in NEPs such as silver (nAg) and zinc oxide (nZnO) into surface water is estimated at approximately 4.9-1700 t/annually [9]. Elsewhere, it was estimated that 50-95\% of ENMs (nAg and $\mathrm{nTiO}_{2}$ ) are released into water resources along the life cycle of NEPs [10]. Furthermore, environmental concentrations of ENMs in water systems differ from estimates from in silico studies [11-15]. For example, Ag and Ti' predicted environmental concentrations (PECs) are reported, respectively, as 0.7-16 $\mu \mathrm{g} / \mathrm{L}$ [16-19], and 0.014-2.2 $\mu \mathrm{g} / \mathrm{L}$ [18-20], while measured environmental concentrations (MECs) were quantified at 0.03-19.7 $\mu \mathrm{g} / \mathrm{L}$ (Ag) [21-23], 
0.67-150 $\mu \mathrm{g} / \mathrm{L}$ (Ti) [12-14,24-26]. Continuous release of ENMs leads to concentrations of nanopollutants reaching levels that can be hazardous in water resources [27].

In order to address concerns related to nanopollution, a considerable proportion of studies have been undertaken on pristine ENMs [28], but the generated data cannot be directly transferred to ENMs released from NEPs (product-released ENMs) due to differences in physicochemical properties [29]. Differences in physicochemical properties are due to (i) the manipulation of pristine ENMs during preparation for incorporation into NEP, (ii) association of product-released-ENMs with other product components, and (iii) the influence of the NEPs life cycle [28-30]. For example, before incorporation into NEPs (e.g., cosmetics), the surface of $\mathrm{nTiO}_{2}$ are commonly modified with coating agents such as aluminium hydroxide $\left(\mathrm{Al}(\mathrm{OH})_{3}\right)$ or polydimethylsiloxane (PDMS) to facilitate dispersion in the matrix of NEPs, to prevent/reduce photooxidation and generation of reactive oxygen species (ROS) [31]. The behaviour of such functionalised $\mathrm{nTiO}_{2}$ does not resemble pristine ENMs counterparts. Similarly, during the use of NEPs, some of the physicochemical properties of ENMs can be altered after exposure of NEPs (i.e., clothing) to environmental stressors such as ultraviolet and physical forms, the use of fabrics, and how they are washed [32]. For instance, nano-enabled socks that were used released ca 50-100 nm compared to 1-2 nm counterparts released by unused socks [33]. Furthermore, the washing method may also influence the amount and properties of ENMs released from fabrics [34,35].

In that context, scientists focused on examining the environmental risk arising from product-released ENMs, and studies on product-released ENMs and other articles (nanocomposites) have grown from 96 in 2017 [36] to approximately 120 in 2021. The studies illustrate that the concentration of product-released ENMs varies considerably $(0.01-35 \%)$, and so does the size $(<100-385 \mathrm{~nm})$ and other physicochemical properties [36]. Due to the low sample mass/volume attainable after sample preparation and the limited analytical equipment capability to analyse ENMs in complex matrices, fewer studies have optimally characterised product-released ENMs [36,37]. As such, there is a considerable knowledge gap on the exposure characteristics of product-released ENMs, and consequently, robust and realistic risk assessment of product-released ENMs in the environment remains to be established [38,39].

In order to establish and address environmentally realistic risks of product-released ENMs, exposure assessment data need to be strengthened at the various stages of the life cycle of NEPs (production, usage, and end of life) [36,40]. The current study examined the release and exposure characteristics of product-released ENMs from a wide array of NEPs that exhibit a medium to high nanopollution potential toward water resources [6]. The NEPs samples were from the category of health and fitness products: sunscreens, hand sanitiser, body cream, and socks samples. The health and fitness category, specifically personal care products, has been shown to dominate NEPs markets worldwide [3-7]. The selection of NEPs was further influenced by, but not limited to, include a few chemical identities of ENMs, the physicochemical properties of the applied ENMs, and the location of the ENMs within the product; all of which influence the environmental exposure potential of ENMs [6]. By considering the current data gap regarding the environmental risk associated with the use of NEPs, the current study sought to enrich the data on the physicochemical properties of product-released ENMs as an essential component to advance global efforts to determine the probable risk of nanopollutants in aquatic environments.

\section{Materials and Methods}

Six NEPs, namely three sunscreens, SUN1 $\left(\mathrm{nTiO}_{2}+\mathrm{nZnO}\right), \mathrm{SUN} 2-3\left(\mathrm{nTiO}_{2}\right) ;$ body cream CA1 $\left(\mathrm{nTiO}_{2}+\mathrm{nAg}\right)$; sanitiser; $\mathrm{SAN} 1(\mathrm{nAg})$; and socks SK1 $\left(\mathrm{nTiO}_{2}+\mathrm{nAg}\right)$ were purchased from South African retailers. The physicochemical properties of the ENMs incorporated in the six NEPs varied and were previously reported [41]. Briefly, SUN1 contained elongated $\mathrm{nTiO}_{2}$, and angular $\mathrm{nZnO}$ particles sized $14 \times 62 \mathrm{~nm}$ and $35 \times 38 \mathrm{~nm}$, respectively. SUN2 and SUN3 contained angular-shaped $\mathrm{nTiO}_{2}$ with a size range of 
20-28 $\times 27-32 \mathrm{~nm}$ and 20-28 $\times 27-32 \mathrm{~nm}$, respectively. Near-spherical $\mathrm{nAg}$ particles with the size range of 22-37 $\mathrm{nm}$ were observed in SAN1. CA1 and SK1, respectively, contained $\mathrm{nTiO}_{2}$ particles sized at $8 \times 53 \mathrm{~nm}$ (elongated) and 32-203 $\times 48-135 \mathrm{~nm}$ (angular), the NEPs also contained near-spherical $\mathrm{nAg}$ ranging $18-28 \mathrm{~nm}$. The particles were negatively charged, and the $\mathrm{nTiO}_{2}$ phase was rutile or anatase. The total amounts of ENMs differed between NEPs [41].

\subsection{Procedures for ENMs Release}

The procedures used to investigate the release of ENMs from NEPs differed and are described in Sections 2.1.1 and 2.1.2. In all instances, the procedures were adapted to simulate conditions (but not fully replicate actual life cycle stages) that promote ENMs release from the NEPs. However, some stages applicable during the use of current NEPs (e.g., application of sunscreen or sanitiser to the skin, prior wearing of socks) were eliminated as the primary focus of the study was the analytical determination of the potential for ENMs release. Furthermore, simple (or standard) aqueous media were preferred to avoid physicochemical complexation, which occurs when using complex media and uncharacterised commercial detergents [42]; however, release evaluations in complex media with greater environmental realism are the cornerstone of nanotechnology risk assessment and are recommended for future studies as analytical capabilities and access advances. All investigations were carried out in triplicate.

\subsubsection{Release of ENMs from Suncreen 1-3 (SUN1-3) and Body Cream 1 (CA1)}

The release of ENMs from SUN1-3 and CA1 followed a slightly modified protocol of Botta et al. [43]. Briefly, $2 \mathrm{~g}$ of SUN1-3 and CA1 were aged in $180 \mathrm{~mL}$ of release media for $48 \mathrm{~h}$ at $25{ }^{\circ} \mathrm{C}$ under darkness (plastic beakers were capped and covered with heavy-duty aluminum foil) and under illumination: -6000 lux (uncapped transparent plastic beakers). The SUN1-3 ENMs were released in Milli-Q water $(18 \mathrm{M} \Omega \cdot \mathrm{cm})$, freshwater, seawater or swimming pool water (S1.1), while the CA1 ENMs were released using Milli-Q water only; the properties of the release media are given in S1.1. ENMs were released by agitating the suspension at $400 \mathrm{rpm}$ for $48 \mathrm{~h}$, and the sample volume was maintained by continuously adding aqueous media throughout the $48 \mathrm{~h}$. Agitation was stopped after $48 \mathrm{~h}$, and the samples were allowed to settle for another $48 \mathrm{~h}$, a step that caused sedimentation that resulted in two phases (surface suspension and sediment); the overall duration of ENMs release was $96 \mathrm{~h}$. The two phases were separated by sampling $150 \mathrm{~mL}$ of stable suspension; the sediments were not disturbed during sampling. The stable suspensions were prepared for product-released ENMs analysis (Section 2.2).

\subsubsection{Release of ENMs from Sock1 (SK1) and Sanitiser1 (SAN1)}

The release of ENMs from SK1 was undertaken by adapting previously developed methods $[44,45]$. Briefly, areas (spots/regions) of the sock material marketed and experimentally confirmed to be incorporated with $\mathrm{nAg}$ and $\mathrm{nTiO}_{2}$ [41] were cut from SK1 samples and transferred into 1 L glass bottles, washed with $200 \mathrm{~mL}$ of the release media (Milli-Q water, tap water, and sodium dodecyl sulfate as a detergent). The detergent media was prepared in two ways: (i) sodium dodecyl sulfate 1, which was prepared in Milli-Q water, while (ii) sodium dodecyl sulfate 2 was prepared in tap water. The samples were washed by shaking at $350 \mathrm{rpm}$ at $40{ }^{\circ} \mathrm{C}$ for $12 \mathrm{~h}$ ( 2 washes). After the final washing cycle, the fabrics were removed from the washing water, and the samples were prepared for analysis (Section 2.2).

For SAN1, ENMs were released following a slightly modified method of Benn et al. [46] and Mackevica et al. [47]. Briefly, $1 \mathrm{mg} / \mathrm{L}$ of the sample was prepared in Milli-Q water and ENMs released by agitating at $350 \mathrm{rpm}$ at $40{ }^{\circ} \mathrm{C}$ for $24 \mathrm{~h}$. After ENMs' release, samples were prepared for analysis (given in Section 2.2).

SUN1 (nZnO), CA1 (nAg), SAN1 (nAg), and SK1 (nAg) were incorporated with ENMs that are relatively soluble. The released ions were recovered from the release media through 
sequential filtration. The samples were sequentially filtered using Amicon ${ }^{\circledR}$ Ultra-15 $30 \mathrm{~K}$ centrifugal filters (30000 MWCO, Merck, South Africa), followed by further centrifugation using Amicon ${ }^{\circledR}$ Ultra-15 3 K centrifugal filter devices (3000 MWCO, Merck, South Africa) for $30 \mathrm{~min}$ at 10,000 rpm for each filtration step. The released ions (filtrates from the $3 \mathrm{~K}$ centrifugal filter device) were quantified (Section 2.2.3).

\subsection{Physicochemical Properties of Product-Released ENMs}

\subsubsection{Electron Microscopy}

Images of product-released ENMs were obtained using a JEOL-JEM 2100 high-resolution transmission electron microscope coupled to energy-dispersive X-ray spectroscopy (HRTEM-EDX) (Tokyo, Japan) fitted with a LaB6 filament operated at $200 \mathrm{kV}$. A Cu grid with a holey carbon film was dipped in the sample solution and air-dried for $12 \mathrm{~h}$, followed by TEM-EDX analysis. Multiple images were captured at different spots on the grid to measure the product-released ENMs' size (minimum particle set at 50) using the ImageJ software.

\subsubsection{Surface Charge of Product-Released ENMs}

A Zetasizer Nano ZS (Malvern Instruments, Worcestershire, United Kingdom) was used to determine the zeta $(\zeta)$ potential of product-released ENMs in the release media, which measured the physicochemical properties reported in Table S1.

\subsubsection{Elemental Analysis}

Elemental analysis of product-released ENMs was performed using inductively coupled plasma mass spectrometry (ICP-MS, Icap Q, Thermo Fisher Scientific, Waltham, United States of America). For total Ti, Zn, Ag, and Si analysis, samples were predigested following a modified MARS 6 Method Note Compendium [48]. Product-released ENMs samples were transferred into digestion vessels, $5.0 \mathrm{~mL}$ of nitric acid $\left(\mathrm{HNO}_{3}\right)(70 \%$, Merck, Johannesburg, South Africa) was added, followed by swirling the vessel and leaving it open for approximately $10 \mathrm{~min}$. After $10 \mathrm{~min}, 2.0 \mathrm{~mL}$ of hydrogen peroxide $\left(\mathrm{H}_{2} \mathrm{O}_{2}\right)(37 \%$, Merck, Johannesburg, South Africa) and hydrofluoric acid (HF) (49\%, Merck, Johannesburg, South Africa) were added to samples containing Ag and Ti, respectively. The microwave digestion program followed the cosmetic and textile heating program highlighted in the MARS 6 Method Note Compendium [48]. All product-released ENMs' digests were filtered using a $0.45 \mu \mathrm{m}$ filter syringe (Merck, Johannesburg, South Africa) and prepared for ICP-MS analysis, monitoring ${ }^{66} \mathrm{Zn},{ }^{48} \mathrm{Ti},{ }^{107} \mathrm{Ag},{ }^{28} \mathrm{Si},{ }^{27} \mathrm{Al}$, and ${ }^{45} \mathrm{Sc}$ (internal). The performance of the digestion method was evaluated by digesting both bulk ( $\mathrm{Zn}$, Ti and Ag, Anatech instruments, Johannesburg, South Africa) and $\mathrm{nTiO}_{2}$ (Tavo commercial nanocomposite, Merck, Johannesburg, South Africa), Ag (bare and aminated, nanoComposix, San Diego, United States of America) and $\mathrm{ZnO}$ (Z-cote, a commercial nanocomposite, BASF, Johannesburg, South Africa). The recovered filtrates were acidified ( $5 \%$ using $\mathrm{HNO}_{3}$ ) and directly analysed for the dissolved ions. Appropriate sample dilutions were performed prior to analysis.

\subsection{Data Analysis}

Statistical analysis and drawing of graphs were performed using GraphPad Prism8 version 8.4.3 for Windows (GraphPad Software, La Jolla, San Diego, United States of America). Student's t-test and two-way ANOVA with Tukey's HSD post hoc test were applied to examine differences between samples, with significance tested at $\alpha=0.05$.

\section{Results and Discussion}

\subsection{Characterisation of Product-Released ENMs}

The release methods used in the current study successfully released ENMs from all NEPs as confirmed in all exposure media variants (Sections 3.1.1-3.1.3). 


\subsubsection{Sunscreen 1-3 (SUN1-3) Product-Released ENMs}

Product-released ENMs in different release media (Milli-Q, freshwater, swimming pool water, and seawater) obtained under light conditions are provided in Figure 1 (TEM images) and Figure S1 (elemental profile). TEM images and elemental profiles of productreleased ENMs obtained under dark conditions are given in Figures S2 and S3, respectively. Variation of illumination conditions and release media did not influence the morphology of product-released ENMs. SUN1-released $\mathrm{nTiO}_{2}$ were elongated, while $\mathrm{nZnO}$ was angular in shape. SUN2-3-released $\mathrm{nTiO}_{2}$ were angular in shape, shapes that were previously reported [41].
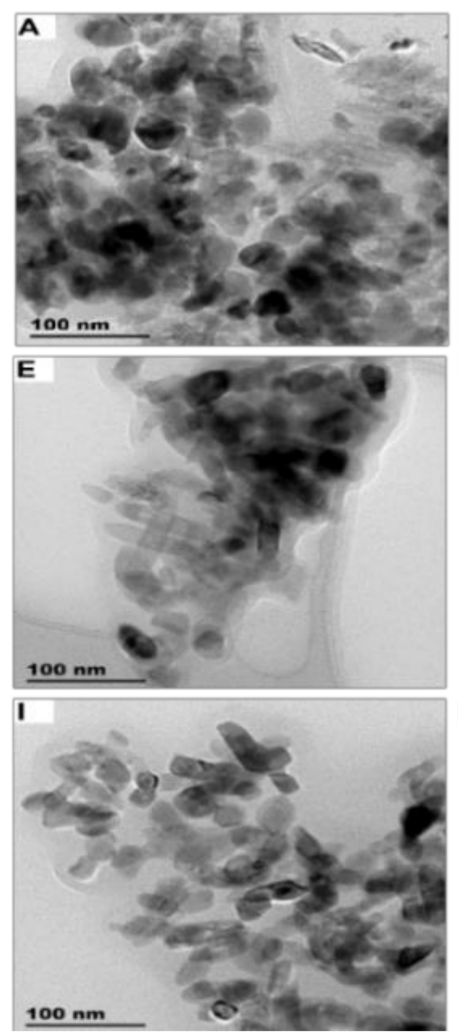
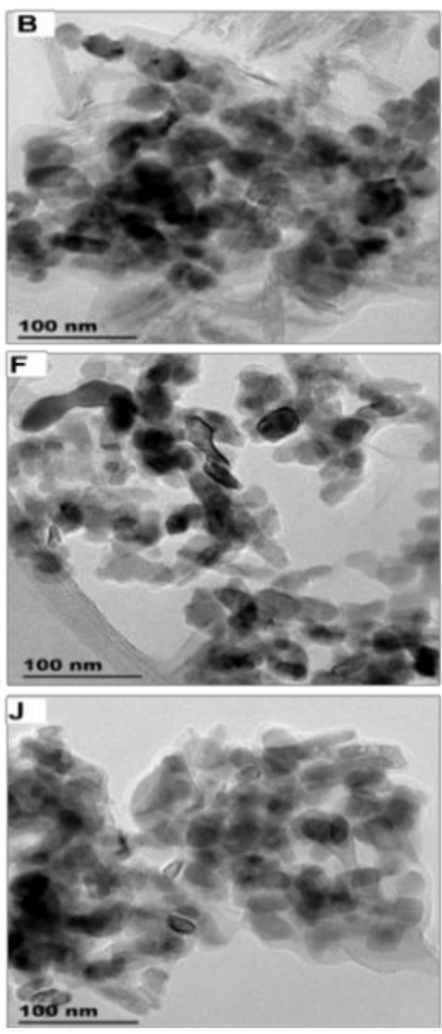
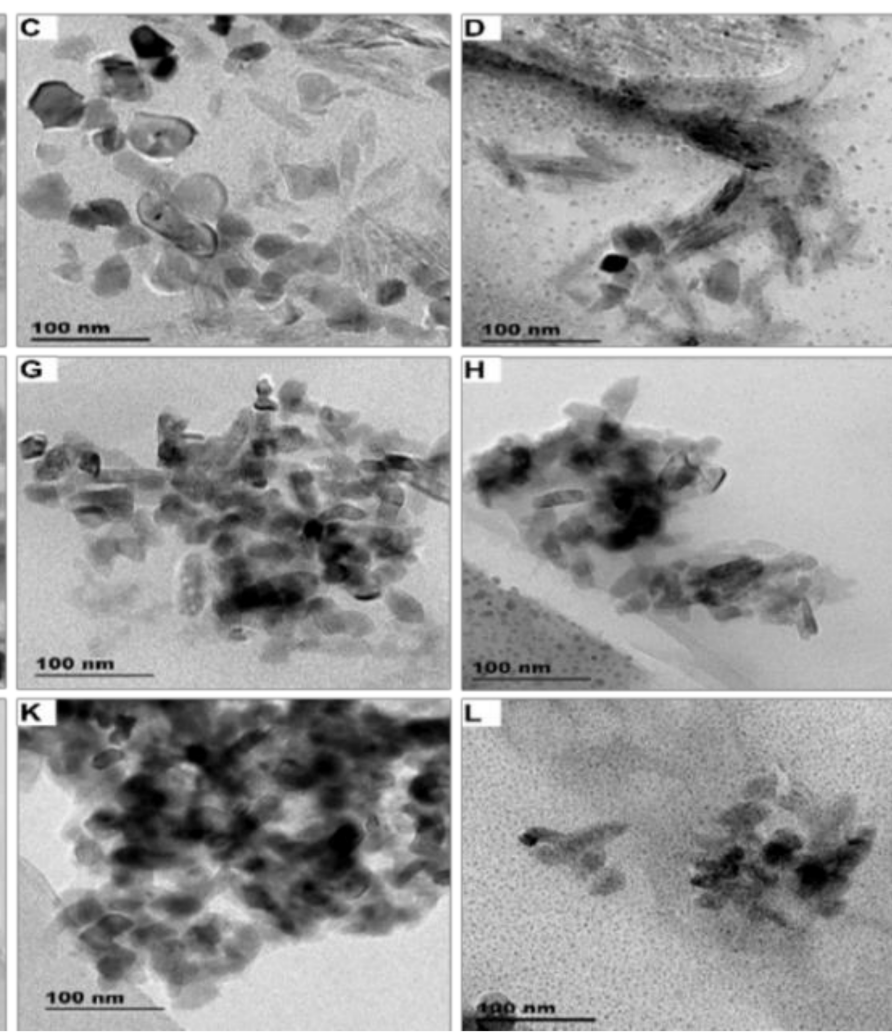

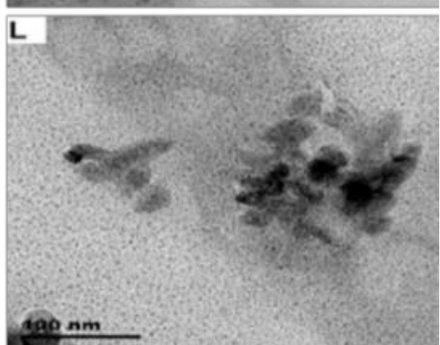

Figure 1. TEM images of product-released ENMs obtained under light conditions for SUN1 detected in Milli-Q water (A), freshwater (B), swimming pool water (C), seawater (D), SUN2 detected in Milli-Q water (E), freshwater (F), swimming pool water $(\mathbf{G})$, seawater $(\mathbf{H})$ and SUN3 detected in Milli-Q water $(\mathbf{I})$, freshwater $(\mathbf{J})$, swimming pool water $(\mathbf{K})$, seawater $(\mathbf{L})$.

Product-released ENMs were still predominantly associated with aluminium (Al) and silicon (Si) (Figures S1 and S3), indicative of remnants of coating agents [49-51], either intact on the surface of product-released ENMs or in the release media. The intensities of the $\mathrm{Al}$ and Si peak varied between the release media and the type of sunscreen (Figures S1 and S3), demonstrating that the release media or exposure conditions affected the ENMs coating agents differently.

The findings confirmed that product-released ENMs were not released in naked forms (pristine ENMs), supporting previous reports that product-released ENMs are commonly released associated the matrix of NEPs (transformed state) [14,42]. For example, in SUN1, Si appeared to have been predominantly released into the media, while Al partially remained adsorbed in product-released $\mathrm{nTiO}_{2}$ (Figure S4). In SUN2 and SUN3, Si remained mainly attached to product-released $\mathrm{nTiO}_{2}$ (Figure S5). The desorption of the coating agents from product-released ENMs surface has implications for the exposure potential of ENMs in aquatic environments, as they influence their reactivity [52], bioavailability and toxicity to aquatic organisms [53-55]. The findings partly illustrated that the environmental exposure characteristics arising from the use of NEPs could not be accurately established from 
studies using pristine ENMs, which leads to the need for refinement and standardisation of ENMs release protocols to improve exposure assessment data.

Similar to the shape of the released ENMs, the sizes (width $\times$ length) were also unaffected by both illumination and release media (Table 1 and Figure S6). The average size of SUN1-released $\mathrm{nZnO}$ was $32-36 \times 32-40 \mathrm{~nm}$, while product-released $\mathrm{nTiO}_{2}$ were 7-9 $\times 66-70 \mathrm{~nm}$. The SUN2-released ENMs sizes were $27-30 \times 33-37 \mathrm{~nm}$, while SUN3released ENMs were 21-22 × 25-28 nm. The average size of SUN2-released ENMs was in agreement with previously reported sizes [41]. The distribution of the SUN1-released $\mathrm{nZnO}$ particles $(\mathrm{W} \times \mathrm{L})$ in Milli-Q water and freshwater were comparable, and the distribution densities were similar to the ENMs incorporated in SUN1. SUN1-released nZnO distributions $(\mathrm{W} \times \mathrm{L})$ in seawater and swimming pool water were similar; the distribution (upper and lower quartiles and violin density) was comparable to the ENMs found in SUN1. The particle distributions of SUN1-released $\mathrm{nTiO}_{2}(\mathrm{~W} \times \mathrm{L})$ were similar in all media. The upper and lower quartiles of the SUN1-released $\mathrm{nTiO}_{2}(\mathrm{~W} \times \mathrm{L})$ distribution slightly varied; the ENMs in SUN1 but were comparable in violin density [41]. In all release media, the product-released $\mathrm{nTiO}_{2}$ distribution profiles of SUN2 and SUN3 were also similar and generally comparable to ENMs in the respective SUNs. While the distribution profiles in all SUN's were comparable to ENMs in NEPs, few exceptions, especially on violin shape/structure and quartiles, were observed.

Table 1. Particle shape and the average size of product-released ENMs in different release water media. ${ }^{\mathrm{a}}$ and ${ }^{\mathrm{b}}$ are the sizes of product-released ENMs obtained under light and dark conditions, respectively.

\begin{tabular}{ccccccc}
\hline \multicolumn{2}{c}{ Release Media } & & Milli-Q Water & Freshwater & Swimming Pool Water & Seawater \\
\hline Sample & ENMs Type & ENMs Shape & Size (nm) & Size (nm) & Size (nm) & Size (nm) \\
\hline \multirow{3}{*}{ SUN1 } & $\mathrm{ZnO}^{\mathrm{a}}$ & Angular & $34 \pm 6 \times 37 \pm 7$ & $35 \pm 9 \times 32 \pm 8$ & $38 \pm 7 \times 39 \pm 5$ & $36 \pm 4 \times 40 \pm 7$ \\
& $\mathrm{ZnO}^{\mathrm{b}}$ & Angular & $37 \pm 9 \times 39 \pm 8$ & $36 \pm 4 \times 37 \pm 4$ & $37 \pm 9 \times 39 \pm 9$ & $43 \pm 6 \times 42 \pm 9$ \\
& $\mathrm{TiO}_{2}{ }^{\mathrm{a}}$ & Elongated & $7 \pm 2 \times 66 \pm 6$ & $9 \pm 2 \times 66 \pm 7$ & $9 \pm 3 \times 67 \pm 9$ & $8 \pm 2 \times 70 \pm 7$ \\
& $\mathrm{TiO}_{2}{ }^{\mathrm{b}}$ & Elongated & $10 \pm 2 \times 68 \pm 6$ & $9 \pm 3 \times 64 \pm 7$ & $9 \pm 3 \times 64 \pm 5$ & $9 \pm 2 \times 67 \pm 8$ \\
SUN2 & $\mathrm{TiO}_{2}{ }^{\mathrm{a}}$ & Angular & $30 \pm 4 \times 33 \pm 7$ & $30 \pm 4 \times 34 \pm 5$ & $27 \pm 6 \times 35 \pm 6$ & $29 \pm 4 \times 37 \pm 4$ \\
& $\mathrm{TiO}_{2}{ }^{\mathrm{b}}$ & Angular & $31 \pm 7 \times 36 \pm 7$ & $29 \pm 6 \times 32 \pm 8$ & $31 \pm 4 \times 35 \pm 8$ & $32 \pm 4 \times 38 \pm 8$ \\
\multirow{3}{*}{ SUN3 } & $\mathrm{TiO}_{2}{ }^{\mathrm{a}}$ & Angular & $21 \pm 5 \times 25 \pm 5$ & $22 \pm 4 \times 25 \pm 5$ & $22 \pm 4 \times 28 \pm 5$ & $21 \pm 6 \times 26 \pm 5$ \\
& $\mathrm{TiO}_{2}{ }^{\mathrm{b}}$ & Angular & $22 \pm 5 \times 28 \pm 6$ & $27 \pm 4 \times 25 \pm 7$ & $26 \pm 5 \times 26 \pm 6$ & $23 \pm 5 \times 26 \pm 6$ \\
\hline
\end{tabular}

Product-released ENMs of all sunscreens were negatively charged, illustrating that, as expected, illumination did not influence the surface charge (under light: Figure 2 and dark: Figure S7). Although all product-released ENMs were negatively charged, the stability of product-released ENMs varied between the release media. Relatively high $\zeta$ potentials (negative or positive, a minimum value of $22 \mathrm{mV}$ ) are considered electrically stable, while lower $\zeta$ potentials are less stable and can lead to rapid agglomeration of nanoparticles [56]. All sunscreen-released ENMs were stable in Milli-Q and freshwater and unstable in seawater and swimming pool water. The difference in the stability of sunscreenreleased ENMs is well corroborated with the TEM-EDX results (Figures S1 and S3), where the coating agents of product-released ENMs were affected differently by the different release media. ENMs are functionalised with coating agents to improve stability [57]; therefore, alteration of the ENMs coating agents will directly affect the stability of ENMs and their fate in aquatic systems [58,59].

The findings of the current study were comparable to previous reports. For example, the size range of elongated product-released $\mathrm{nTiO}_{2}$ obtained in the current study was comparable to the range $(10 \times 139 \mathrm{~nm})$ of sunscreen-released $\mathrm{nTiO}_{2}$ (elongated) previously reported $[42,43]$. The negative surface potential of sunscreen-released ENMs was also previously reported $[43,60]$. 


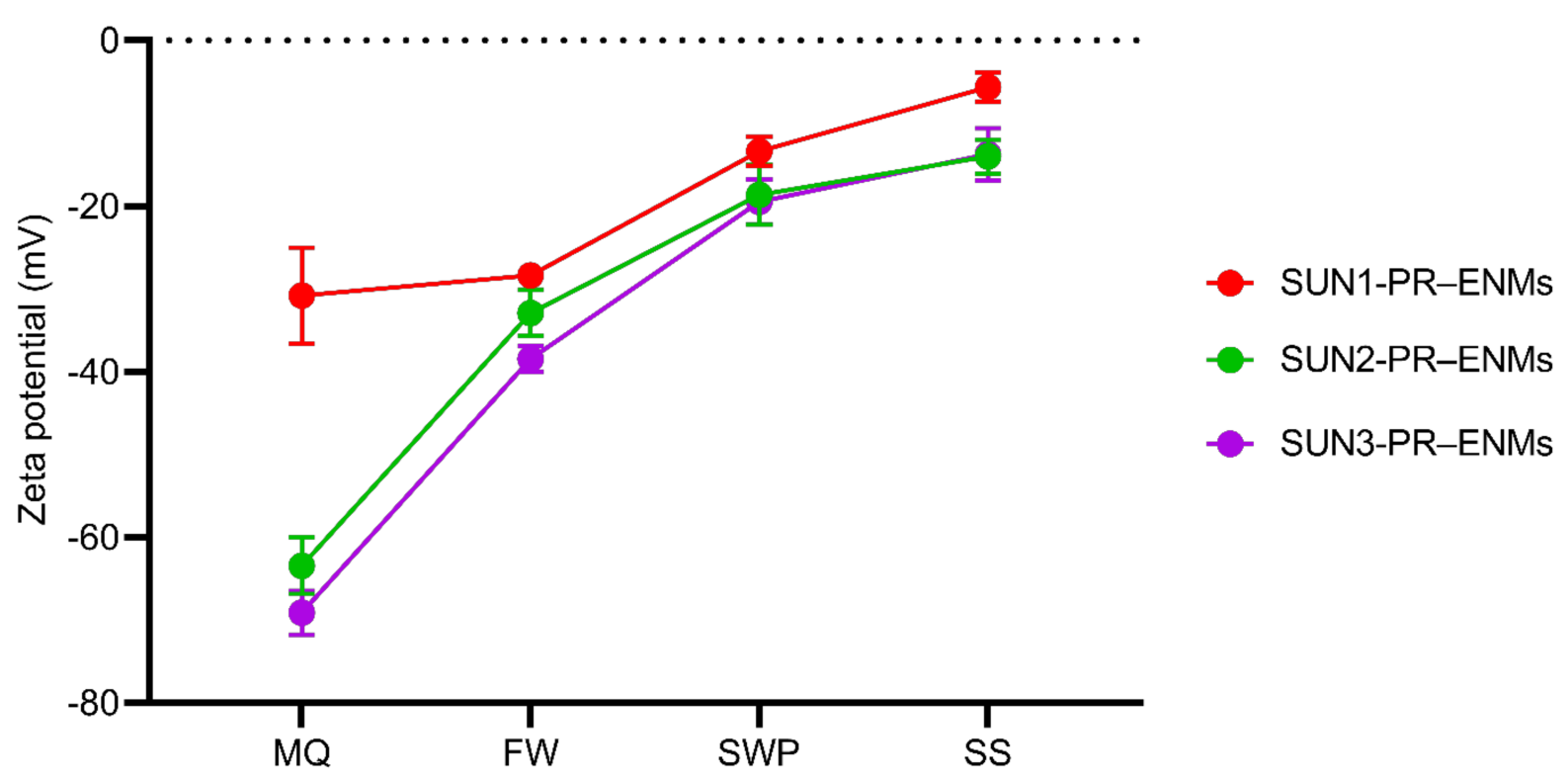

Figure 2. Zeta potential of product-released ENMs (PR-ENMs) obtained under light conditions in different release media of Milli-Q water (MQ), freshwater (FW), swimming pool water (SWP), and seawater (SS).

\subsubsection{Sanitiser 1 (SAN1) and Body Cream (CA1) Product-Released ENMs}

SAN1 and CA1 ENMs were successfully released into the respective media, as shown in Figure 3 and Figure S8 (size distribution of product-released ENMs). SAN1-released nAg were near-spherical and averaged $10 \pm 2$ and $23 \pm 4 \mathrm{~nm}$, indicating distinct size classes. The SAN1-released nAg generated two distribution profiles that differed in the upper quartiles; one of the profiles was comparable to the ENMs in SAN1 [41]. The other distribution differs from the ENMs profile in SAN1 on width, indicating possible agglomeration. The SAN1-released $\mathrm{nAg} \zeta$ p potentials were determined to be $-32.5 \pm 2.1 \mathrm{mV}$.

Binary CA1-released $\mathrm{nTiO}_{2}$ and CA1-released $\mathrm{nAg}$ were detected under both illumination conditions (Figure 4 and Figure S9), the Si peak of the coating agents was also detected. The CA1-released $\mathrm{nTiO}_{2}$ were elongated in shape and had an average size of $8 \pm 3 \times 60 \pm 13 \mathrm{~nm}$ (under light) and $9 \pm 3 \times 66 \pm 9 \mathrm{~nm}$ (under dark), indicating that the size was not affected by variation in illumination. Near-spherical CA1-released nAg were detected in three distinct average sizes of $12 \pm 3,27 \pm 7$, and $49 \pm 9 \mathrm{~nm}$ under light conditions, relative to $10 \pm 3,28 \pm 8$, and $54 \pm 8 \mathrm{~nm}$ under dark conditions, indicating that illumination variation did not affect ENMs sizes. The distribution and the violin density of CA1-released nAg obtained under light and dark conditions were similar. The distribution density of the CA1-released nAg and ENMs was comparable, but differed in the upper quartiles, indicating possible particle transformation. Similarly, the distribution of CA1 released $\mathrm{nTiO}_{2}$ was comparable, except in the lower quartiles of CA1 released $\mathrm{nTiO}_{2}$ obtained under dark conditions. CA1-released ENMs obtained under light and dark conditions were negatively charged at $-23.6 \pm 1.3$ and $-22.8 \pm 1.2 \mathrm{mV}$, respectively. 

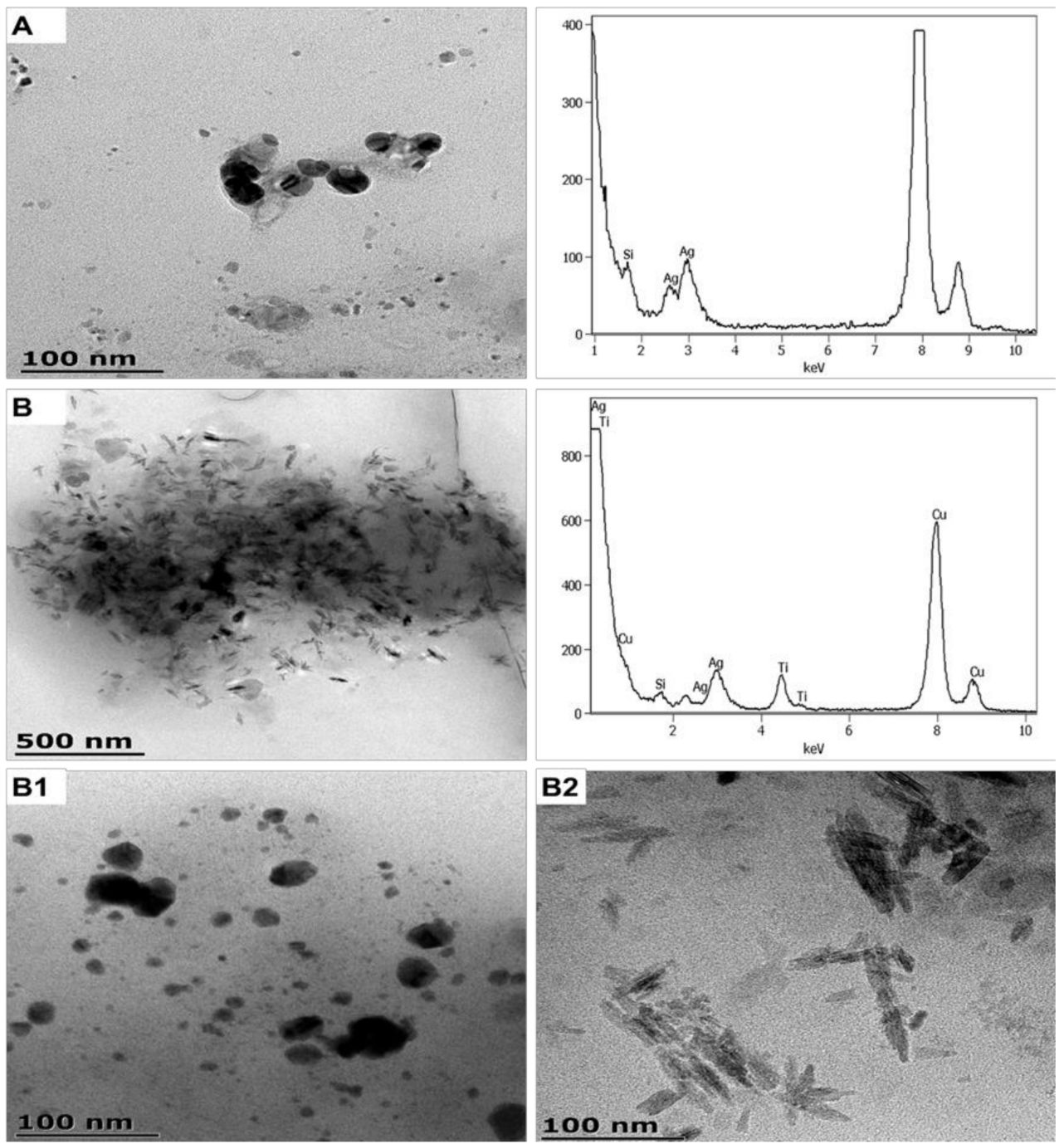

Figure 3. TEM-EDX illustrating SAN1-released ENMs (A) and binary CA1-released ENMs obtained under light conditions (B). (B1,B2) are higher magnification of image B showing product-released $\mathrm{nAg}$ and product-released $\mathrm{nTiO}_{2}$, respectively.

The presence of different product-released nAg size classes indicated that the ENMs were transformed during release, since the primary size of the ENMs incorporated in the NEPs averaged $21.7 \pm 6$ (CA1) and $22 \pm 7 \mathrm{~nm}$ and $37 \pm 4 \mathrm{~nm}$ (SAN1) [41]. In aquatic environments, pristine $\mathrm{nAg}$ are susceptible to undergo various transformations [61], including oxidative dissolution and reformation of Ag particles, leading to the formation of particles of different sizes [62,63]. Peretyazhko et al. [64] found that after the dissolution of pristine $\mathrm{nAg}$, the size of the particles increased due to Ostwald ripening. In the case of particle size decrease, some studies attributed the reduction to the dissolution of $\mathrm{nAg}$, followed by the reduction-driven formation of smaller $n \mathrm{Ag}[65,66]$. Furthermore, it was shown that in the absence of environmental factors such as ultraviolet radiation and environmental ligands, a simple dilution of concentrated nAg suspensions and colloidal Ag-based products such as SAN1 can cause particle destabilisation leading to the formation of agglomerates and the reduction in particle size $[67,68]$. The change in the particle size of $\mathrm{nAg}$ incorporated into body cream and mouth spray in artificial sweat and saliva was previously reported [69]; product-released ENMs experienced significant growth in size from 5 to $25 \mathrm{~nm}$ to 10 to $800 \mathrm{~nm}$. 

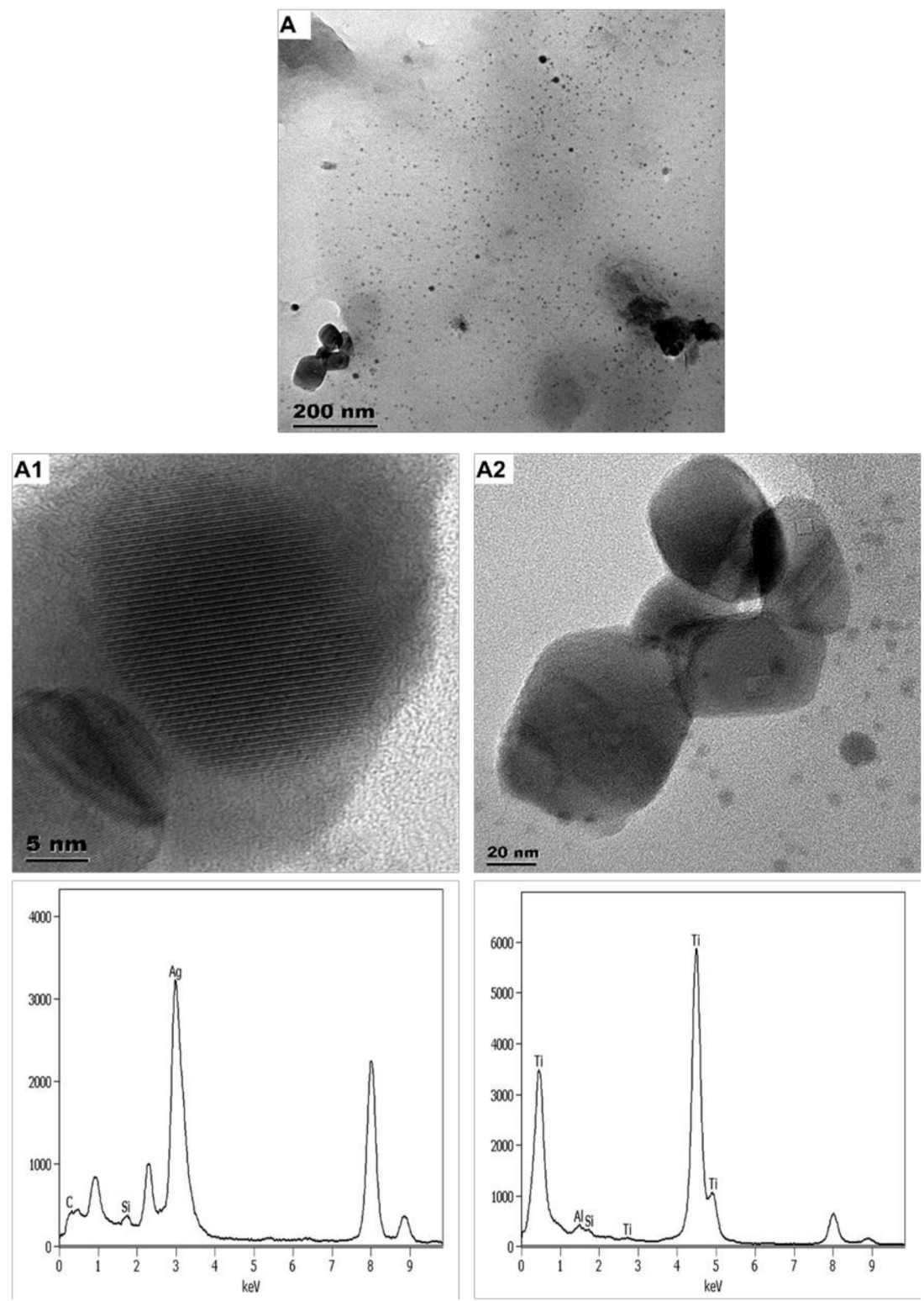

Figure 4. Images and respective spectra obtained from TEM-EDX characterisation of SK1-released ENMs (A). Images (A1,A2) are high magnification of image A, specifically showing near-spherical SK1-released $\mathrm{nAg}$ and angular SK1-released $\mathrm{nTiO}_{2}$ particles, respectively.

Environmental exposure to product-released ENMs in aquatic environments has been reported mainly from commercial clothing [70,71], personal care products (toothbrushes, toothpaste, face masks, shampoo, and detergents) [46,47], and paints [72]. The sizes of personal care-released nAg and paint-released nAg were $42-500 \mathrm{~nm}[46,47]$ and $<15-100 \mathrm{~nm}$ [72], respectively. Similar to most release studies, the product-released nAg were still embedded in the NEPs' matrix. Herein, the SAN1-released nAg did not appear to be embedded in the product matrix and were individually isolated or agglomerated; such findings further illustrate that ENMs release potential is influenced by their loci in products and product formulation. CA1-released ENMs were often visualised to be encircled by a layer that could not be accurately identified, whether being components of the NEP's matrix or ENMs coating agents; however, it is worth noting that Si was detected in the sample by EDX (Figure 4). The physicochemical state at which the product-released ENMs were detected in aqueous environments was predominantly related to the matrix of NEPs. For example, SAN1 was a clear liquid suspension with a viscosity comparable to water, while CA1 was a semi-solid cream made up of organic compounds. 


\subsubsection{Socks 1 (SK1) Product-Released ENMs}

Washing SK1 released binary ENMs $\left(\mathrm{nTiO}_{2}\right.$ and $\mathrm{nAg}$ ) (Figure 4). SK1-released $\mathrm{nAg}$ were near-spherical and angular in shape and averaged $8 \pm 4 \mathrm{~nm}$ and $21-76 \times 29-77 \mathrm{~nm}$, respectively. The angular particles were smaller and rapidly agglomerated. SK1-released $\mathrm{nTiO}_{2}$ were angular and averaged $80 \pm 25 \times 79 \pm 29 \mathrm{~nm}$ (Figure S10). The distribution of SK1-released $\mathrm{nTiO}_{2}$ and the spherically shaped SK1-released nAg and the respective ENMs in SK1 are comparable. The profile of angular/irregular shaped SK1-released nAg and nAg in SK1 slightly differs, an expected observation since nAg size was affected by the ashing procedure [41].

SK1-released ENMs were coated with $\mathrm{Si}$, and $\mathrm{Al}$, and the coating agents were found to be intact on some SK1-released ENMs (Figure S11). Similar to the previous productreleased ENMs (in the preceding sections), the SK1-released ENMs' surface was negatively charged $(-33.0 \pm 2.1 \mathrm{mV})$. The current findings are in agreement with previous reports, whereby product-released $\mathrm{nAg}(20-40 \mathrm{~nm})$ and product-released $\mathrm{nTiO}_{2}(60-350 \mathrm{~nm})$ were detected after washing nano-enhanced textiles [70,71].

It is worth mentioning that considerable analytical challenges were initially experienced during the characterisation of SK1-released ENMs. First, SK1-released ENMs were not detected (TEM-EDX) without a pre-enrichment step, especially for SK1-released nAg. After sample enrichment, small particles $(\sim 4-6 \mathrm{~nm})$ were imaged but could not be identified because the EDX beam rapidly destroyed them. Finally, the washing detergent introduced a thick layer that concealed the SK1-released ENMs underneath (Figure S12). To improve TEM-EDX characterisation, the number of SK1 units washed concurrently was increased; for this part, the release media was limited to Milli-Q water. Increasing the number of SK1 samples washed simultaneously and concentrating the sample through centrifugation improved TEM-EDX characterisation and enabled SK1-released ENMs particle size quantification.

Overall, the characterisation of product-released ENMs showed that all NEPs investigated in the present study are potential nanopollution sources for water resources. The shapes of the respective product-released ENMs were similar to the ENMs incorporated into the respective NEPs, whose physicochemical properties were previously reported [41]. The sizes of SUNs-released ENMs were comparable to the sizes determined in the NEPs [41]. However, in the case of CA1, SAN1, SK1, the product-released ENMs sizes were slightly different from the ENMs incorporated into the NEPs [41], especially for $n A g$, where the transformation occurred in terms of the change in particle size (increase and decrease). The physical properties of product-released ENMs are crucial in understanding the behaviour, fate and effects of nanopollutants in aquatic environments, where several studies have already reported their presence in real environmental samples [13,14,73-75].

\subsection{Elemental Quantification of Product-Released ENMs}

The digestion, analysis, and recovery method of nano- and bulk reference standards were within the acceptable ranges of (75-107\%) $\mathrm{Ti},(72-97 \%) \mathrm{Ag}$, (74-98\%) Zn, (70-91\%) $\mathrm{Al}$ and $(70-87 \%) \mathrm{Si}$.

\subsubsection{Sunscreen 1-3 (SUN1-3) Product-Released ENMs}

The total concentration of $\mathrm{Ti}, \mathrm{Zn}$, and $\mathrm{Zn}^{2+}$ released relative to the initial amount of ENMs added to the sunscreens varied and ranged in general between 0.4 and $8 \%(w / w)$ (Figure 5). SUN1-3 released Ti at different extents; in most exposure scenarios, SUN3 > SUN2 > SUN1. In addition to Ti release, SUN1 simultaneously released $\mathrm{Zn}$ and $\mathrm{Zn}^{2+}$ in the range of $0.67-5.7 \%(w / w)$ and $0.5-3.0 \%(w / w)$, respectively (Figure 6). The amounts of $\mathrm{Zn}$ and $\mathrm{Zn}^{2+}$ in the respective product-released ENMs release media were mostly different (Figure 6). Indicative that SUN1 generally releases $\mathrm{Zn}$ in particulate and ionic forms. 


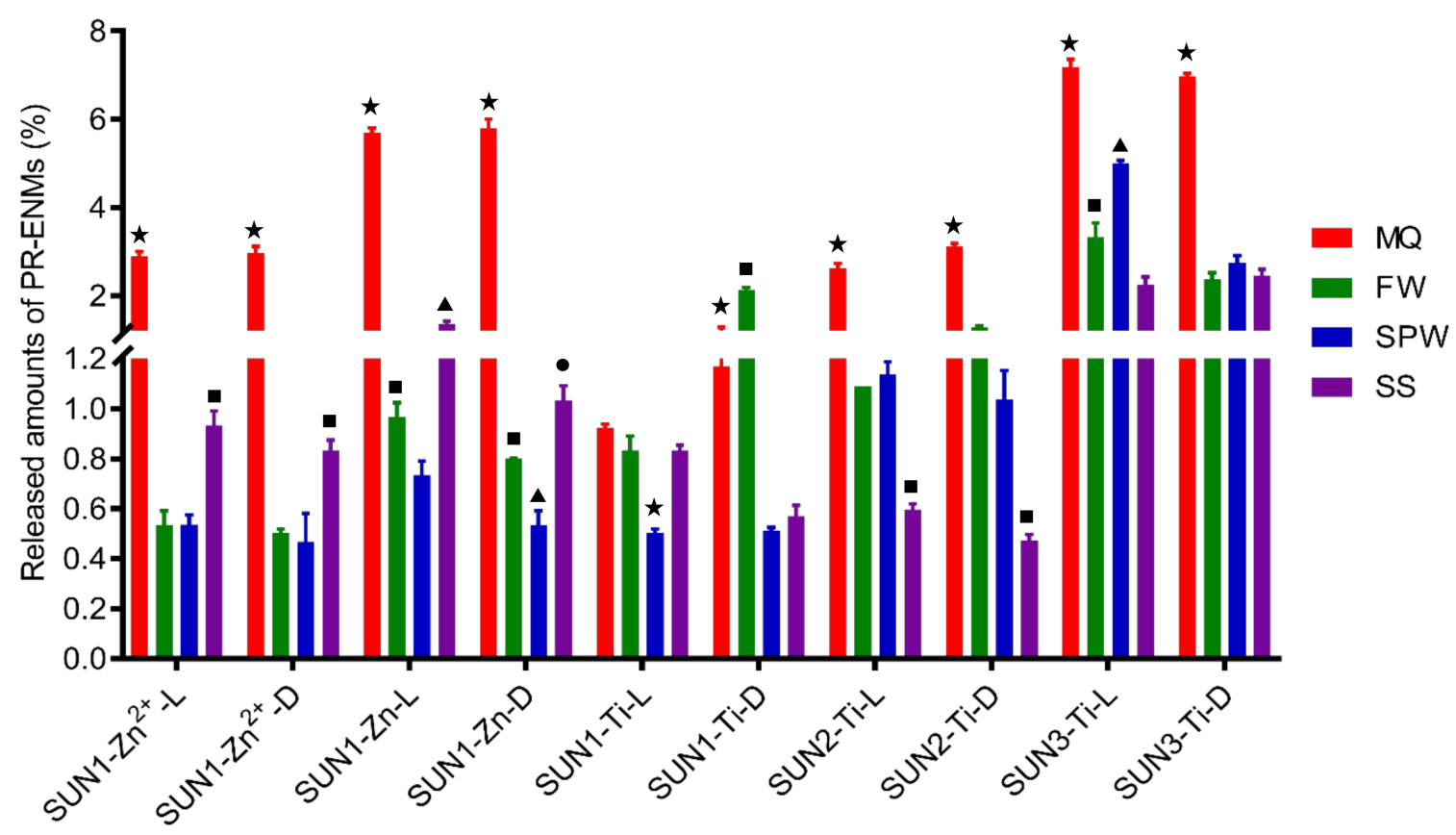

Figure 5. The amount of $\mathrm{Zn}^{2+}, \mathrm{Zn}$, and Ti released from SUN1-3 in different release media (Milli-Q water (MQ), freshwater (FW), swimming pool water (SPW), and seawater (SS) under light (L) and dark (D) conditions. The differing of symbols ( $\star$

- A) on top of error bars indicates statistical difference $(p<0.05)$ between the release media treatments.

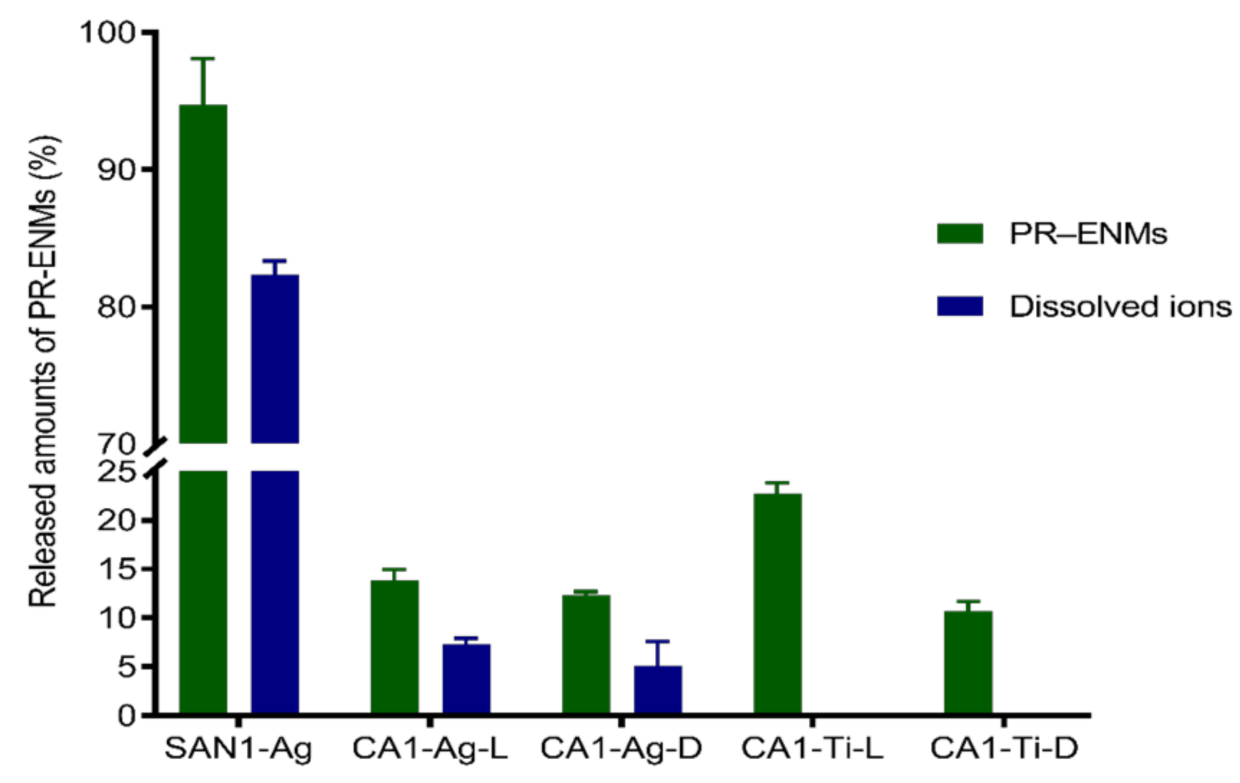

Figure 6. The amounts of SAN1 and CA1-released nAg and released Ag ions; L and D denote light and dark conditions, respectively.

The amounts of $\mathrm{Ti}, \mathrm{Zn}$, and $\mathrm{Zn}^{2+}$ released from sunscreens were influenced by nature of the NEPs formulation (the initial amount present in the NEP matrix and the product matrix) and simulated environmental conditions (water chemistry and variation in illumination). The influence of the initial amount present in the NEPs was observed between SUN2 and SUN3 (being of the same brand). SUN3, which contained more $\mathrm{nTiO}_{2}$ [1.6\% $(w / w)]$ compared to SUN2 [0.95\% $(w / w)]$ [41], released relatively higher amounts of $\mathrm{Ti}(p=0.0001-0.01)$. A further comparison of the amount of Ti released by SUN1-3 showed that the NEPs matrix also influenced Ti release. Although SUN1 contained relatively more $\mathrm{nTiO}_{2}[4.31 \%(w / w)]$ than SUN2-3 [<3\% $\left.(w / w)\right][41]$, the total amounts of Ti released from 
SUN1 were lower than SUN2-3 (Figure 6) - probably an influence of the formulation of the product on the release of ENMs.

In terms of environmental conditions, the amounts of $\mathrm{Ti}, \mathrm{Zn}$, and $\mathrm{Zn}^{2+}$ were mainly influenced by water chemistry rather than illumination variations; illumination rarely influenced the amounts released. In descending order, the amount of Ti released from SUN1 under light and dark conditions was Milli-Q water $\geq$ freshwater $\geq$ seawater $>$ swimming pool water and freshwater $>$ Milli-Q water $>$ Seawater $\geq$ swimming pool water, respectively. In the case of $\mathrm{Zn}$, the trend of the amounts released under light and dark conditions, in descending order, was Milli-Q water $>$ freshwater $>$ seawater $>$ swimming pool water and Milli-Q water $>$ seawater $>$ freshwater $>$ swimming pool water, respectively. The amounts of $\mathrm{Zn}^{2+}$ followed a descending order of Milli-Q water $>$ seawater $>$ freshwater $\geq$ swimming pool water for both illuminations. The Ti amount trends (descending order) of SUN2 and SUN3 were Milli-Q water $>$ freshwater $\geq$ swimming pool water $>$ seawater and Milli-Q water $>$ swimming pool water $>$ freshwater $\geq$ seawater for both illuminations, respectively.

The ionic strength of the release media probably enhanced the agglomeration and sedimentation rate, thus probably causing the differences in the amount released. The release media influenced the dispersion of the sunscreens in the media was different; for example, in Milli-Q water and freshwater, the sunscreens dispersed thoroughly and turned into a homogeneous milky solution, while in other cases, the sunscreen matrix fragmented and formed flocculates. The difference in the dispersion and sedimentation of the NEPs matrix in the release media has implications for ENMs' exposure dynamics in the aqueous phase, as the two (uniform mixture and flocculates) will have different sedimentation rates; flocs sediment faster due to gravity [76]. Different ENMs sedimentation rates were reported in different water chemistries and are influenced by ionic strength, ionic species, and dissolved oxygen [77].

Overall, the current findings illustrated the varying nanopollution characteristics arising from sunscreen NEPs in different water quality environments and that the degree of nanopollution depends on both the NEPs' matrix properties and recipient resource water quality. Furthermore, the results showed that the product-released ENMs will pollute not only the aqueous phase of aquatic environments but also sediments, in addition to adsorption to abiotic and biotic entities. The sedimentation rate influenced the concentrations detected in the suspension, a factor that will be at play in real water bodies as driven by the velocity of the water and other characteristics. Investigations of ENMs sedimentation were carried out on pristine ENMs, and it was found [78] that $50 \%$ and $70 \%$ of $\mathrm{nTiO}_{2}$ and $\mathrm{nZnO}$ were found to sediment within the first $24 \mathrm{~h}$ and continued to slowly sediment for the next 2 to 14 days in natural water, respectively. Similarly, the study by Botta et al. [43] showed that a significant proportion of sunscreen-released $\mathrm{nTiO}_{2}$ in seawater aggregated and sedimented. The rate of sedimentation influences the exposure dynamics of benthic organisms. Beyond the release stage, the behaviour of product-released ENMs in aquatic environments and the effects on benthic organisms are not well understood and warrant detailed attention. As such, at more robust levels, ENMs exposure assessment must consider aquatic resource characteristics.

\subsubsection{Sanitiser 1 (SAN1) and Body Cream (CA1) Product-Released ENMs}

The amount of $\mathrm{Ag} \mathrm{Ag}^{+}$, and Ti released from SAN1 and CA1 varied (Figure 6). SAN1 released considerably higher amounts of $\operatorname{Ag}$ than CA1 $(p=0.001)$; the characteristics of the NEPs matrix probably caused the observed difference-further illustrating the influential role of the NEPs matrix in the potential for exposure to ENMs. Both SAN1 and CA1 released $\mathrm{Ag}$ in particulate and dissolved forms. The amount of $\mathrm{Ag}$ and $\mathrm{Ag}^{+}$in the respective release media of SAN1 $(p=0.0002)$ and CA1 $(p=0.003-0.005)$ varied, indicating the coexistence of particulate and ionic Ag. CA1 further released Ti amounts higher and comparable to Ag under light $(p=0.02)$ and dark $(p=0.056)$ conditions. 
Some NEPs containing $\mathrm{nAg}$ were classified as having medium to high exposure potential to water resources $[6,7,79]$. The studies reported that toothbrushes released $\mathrm{nAg}$ (5.9-626 ng/L) [47], paints released nAg (30\%) [72], and plush toy exterior fur released $\mathrm{nAg}(<1-35 \%)$ [80]. It is estimated that Ag can be released from products in the range of $25-100 \%$ in wastewater treatment plants [81]. In most cases, the NEPs release Ag in the particulate or ionic form at varying degrees $[47,80]$. The form and extent of Ag release from $\mathrm{nAg}$ are complex because speciation is influenced by various factors, such as particle size, coating agents, and release media characteristics [82-86].

The dissolution of nAg from both NEPs may be due to the small-sized particles incorporated in SAN1 $(10-37 \mathrm{~nm})$ and CA1 $(13-44 \mathrm{~nm})$ and the change in particle size of product-released $\mathrm{nAg}$ (as observed by the detection of particles of different sizes) may have contributed to the degree of dissolution observed in the exposures of SAN1 and CA1. Nanoparticle size reduction was previously reported to result in increased dissolution due to increased surface area $[87,88]$.

\subsubsection{Socks 1 (SK1)-Released ENMs}

SK1 released 0.004-0.100 mg/L and 2.66-5.98 mg/L of total Ag and Ti, respectively (Figure 7). The Ag and Ti concentrations released from SK1 were not normalised back to the initial concentration incorporated into the NEPs because the $\mathrm{Ag}$ and Ti present in different SK1 materials were inconsistent. Incorporation of ENMs of different properties by manufacturers has recently been reported [89]. As illustrated in Figure 7, the amounts quantified in the different wash cycles varied between the release media and fractions. The amounts quantified for particulate fractions in Milli-Q water were not different $(p=0.22-0.67)$. In the case of tap water, the difference was only observed in the $>0.45 \mu \mathrm{m}$ fraction, where a higher Ag concentration was determined in the second cycle. The amount released from sodium dodecyl sulfate 1 and sodium dodecyl sulfate 2 also varied; relatively large amounts were detected in the first cycle for $>0.45 \mu \mathrm{m}(p=0.001-0.03)$ and $<0.45 \mu \mathrm{m}(0.06-0.21)$. For $\mathrm{Ag}^{+}$, only sodium dodecyl sulfate 2 released higher amounts in the first cycle $(p=0.01)$. Released $\mathrm{Ag}^{+}$was detected in comparable amounts between cycles in Milli-Q water, tap water, and sodium dodecyl sulfate $1(p=0.27-0.99)$. As shown in Figure 7 , sodium dodecyl sulfate 1 release media mainly affected $\mathrm{Ag}$ forms, compared to tap water and especially Milli-Q water.

In cases where Ag amounts varied in different fractions, more Ag was detected in $>0.45 \mu \mathrm{m}$, while $<3 \mathrm{kDa}$ was comparable or lower than $<0.45 \mu \mathrm{m}$. Contrary to Ag and $\mathrm{Ag}^{+}$, the amounts of Ti were comparable in the first and second wash cycles for all wash media, except for sodium dodecyl sulfate 1 , where the amounts of Ti were higher in the first cycle. As shown in Figure 7, the amounts of Ti in the different fractions were comparable, except for tap water, sodium dodecyl sulfate 1 and sodium dodecyl sulfate 2 , where the highest amounts were quantified in fractions $>0.45 \mathrm{~m}$ and fractions $>0.45 \mu \mathrm{m}$ and $<0.45 \mu \mathrm{m}$ fractions, respectively. Overall, nAg release was more affected by the simulated washing conditions than $\mathrm{nTiO}_{2}$ incorporated in SK1.

The environmental exposure of particulates and ions of Ag [33-35,44,90,91] and $\mathrm{Ti}[71,92]$, respectively, released from commercial textile products enabled with $\mathrm{nAg}$ or $\mathrm{nTiO}_{2}$ have been investigated, although, in some instances, there were differences between studies. The differences were mainly caused by the assessment of different clothing materials, the type of ENMs nanocomposite, the initial amounts of ENMs added to the NEPs, ENMs incorporation methods, ENMs location within the NEPs, and the chemistry of the release media. 


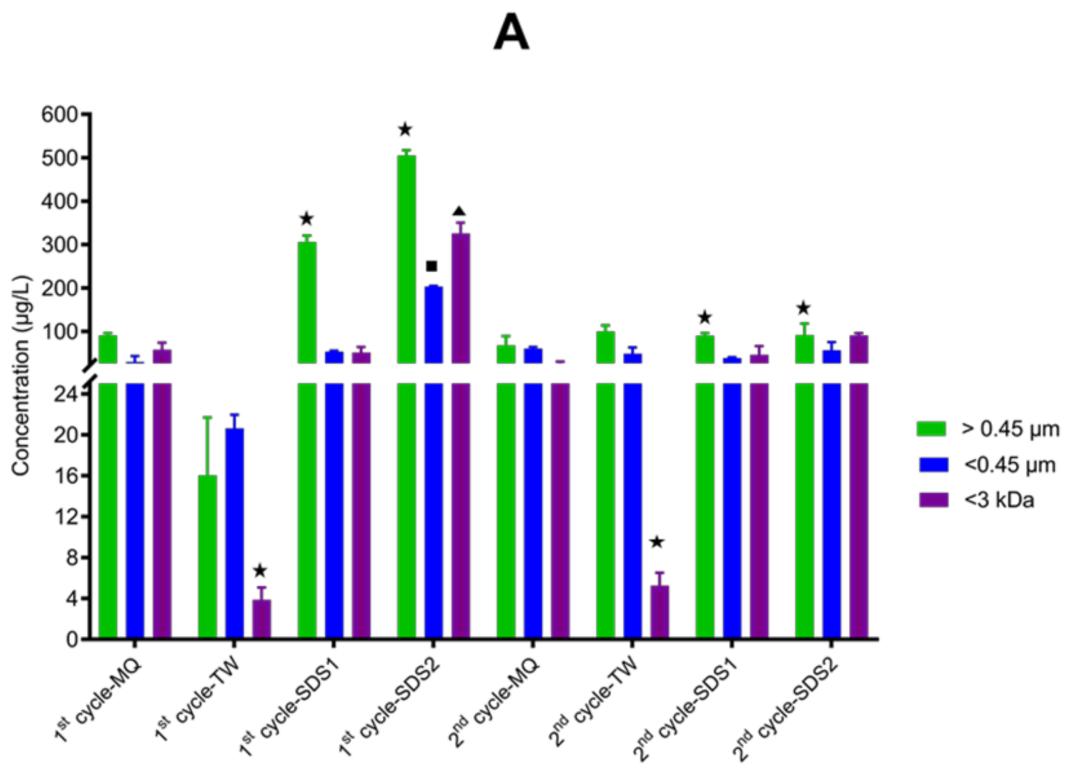

B

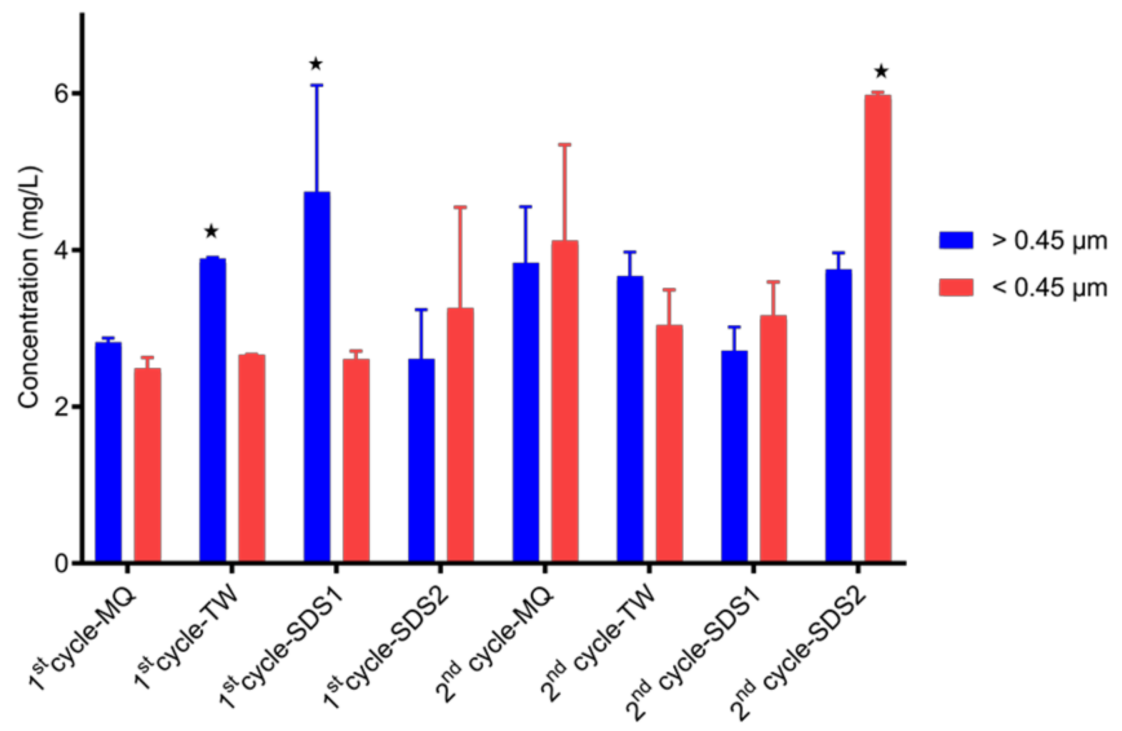

Figure 7. Total amounts of $\mathrm{Ag}(\mathrm{A})$ and $\mathrm{Ti}(\mathbf{B})$ released from SK1 in Milli-Q water (MQ), tap water (TW), sodium dodecyl sulfate 1 (SDS1), and sodium dodecyl sulfate (SDS2) in two wash cycles. The symbol $(\star \square)$ on top of error bars denote statistical difference $(p<0.05)$ between the released Ag and Ti fractions per wash cycle.

Nonetheless, the current study correlated with some previous reports on the high amount of Ag detected mainly in the first wash cycle [14,75,77,80] and the detection of higher amounts of particulate Ag [44]. Thus, elevated ENMs release from fabric NEPs can be expected from initial washes after purchase. Overall, the amounts released in the current study were in agreement with the previous reporting of 0.32-38.5 mg/L for Ag [34,91,93] and $5 \mathrm{mg} / \mathrm{L}$ for $\mathrm{Ti}$ [71]. Exposure assessments of commercial $\mathrm{TiO}_{2}$ nano-enabled textiles compared to $\mathrm{nAg}$-enabled textiles are currently scarce. The high market penetration of $\mathrm{nAg}$ functional textiles and the primary function of $\mathrm{nAg}$ (antimicrobial properties) could be the reason behind the difference in the number of studies undertaken. 


\subsubsection{Release of ENMs Coating}

ENMs coating agents in SUN1-3 (Figures S4 and S5), CA1 (Figure S13) and SK1 (Figure S8) were somewhat desorbed from the surface of ENMs, and the components of the coating agent ( $\mathrm{Si}$ and $\mathrm{Al}$ ) were released into the respective media. The $\mathrm{Si}$ and $\mathrm{Al}$ coating agents of the released ENMs were determined in $<3 \mathrm{kDa}$ filtrate to avoid coating agents still attached to the product-released ENMs. Although TEM-EDX analysis showed that $\mathrm{Si}$ and $\mathrm{Al}$ were coated on the surface of ENMs, the presence of these elements as part of the other matrix of NEPs may exist; for all NEPs, manufacturers neither declared the element nor the quantity. Because of uncertainties, for this exercise, the $\mathrm{Si}$ and $\mathrm{Al}$ are assumed to originate from ENMs coatings and the overall NEPs matrix.

The findings on the extent to which ENMs coating agents were released were recorded in Milli-Q water release media. The amount of Si released varied between the NEPs (Table 2).

Table 2. The concentration of Si released from SUN1-3, CA1, and SK1.

\begin{tabular}{ccc}
\hline \multirow{2}{*}{ Sample Name } & \multicolumn{2}{c}{ Release Amount of Si\% $(w / w)$} \\
\cline { 2 - 3 } & Light Condition & Dark Condition \\
\hline SUN1 & $10.1 \pm 1.4$ & $11.2 \pm 2.5$ \\
SUN2 & $5.4 \pm 0.9$ & $5.7 \pm 0.8$ \\
SUN3 & $3.7 \pm 0.4$ & $3.4 \pm 0.4$ \\
CA1 & $23 \pm 2$ & $19 \pm 6$ \\
\hline
\end{tabular}

Si was detected in the respective release media (SUN1-3 and CA1) in the descending order of CA1 $>$ SUN1 $>$ SUN3 $\geq$ SUN2 under both illumination conditions. The SUN1 ENMs, which were coated with $\mathrm{Si}$ and $\mathrm{Al}$, released $\mathrm{Si}$ in large amounts compared to $\mathrm{Al}$; $\mathrm{Al}$ amounts in the product-released ENMs media of SUN1 were below the detection limit $(\mathrm{LOD}=10 \mu \mathrm{g} / \mathrm{L})$. Elemental concentrations were consistent with the EDX observations, where $\mathrm{Si}$ desorbed and released into the product-released ENMs release media, while Al was still partially attached to the product-released ENMs (Figure S4). Similarly, the low amounts of Si detected in SUN2 and SUN3 corroborated the earlier findings of TEM-EDX (Figure S5), where Si was observed to be still attached to product-released ENMs. In the case of CA1, which released the highest amounts of Si, TEM-EDX analysis (Figure S13) showed that most of the Si disassociated from product-released ENMs. For SK1, the amounts of Si and $\mathrm{Al}$ were determined to be 10 and $4.76 \mathrm{mg} / \mathrm{L}$, respectively, also confirming the release observed with TEM-EDX (Figure S11).

Although ENMs incorporated into NEPs are well known to be enclosed with coating agents [94] and have been shown to be altered during the aqueous ageing of nanocomposites (used in cosmetics) and released into aquatic environments [52,95-97]; the amount of the coating agent components released from NEPs is often not reported. Until recently, nanocomposites intended for NEPs formulations, such as sunscreens, were evaluated [97]; $1.5-2 \%(w / w)$ of Si was released into ultrapure water, while higher amounts of $88-98 \%$ $(w / w)$ were simulated freshwater and seawater. It is imperative that the amounts of released coating agents are quantified and considered when the risks of product-released ENMs are evaluated, as it is currently unclear whether the components of the coating agent influence the product-released ENMs to what extent, and therefore future studies should evaluate their association.

\section{Conclusions}

The study successfully illustrated the nanopollution of water media during the simulated use of NEPs by characterising product-released ENMs from a wide range of products. The product-released $\mathrm{nTiO}_{2}$ were elongated $(7-9 \times 66-70 \mathrm{~nm})$ or angular $(21-80 \times 25-79 \mathrm{~nm})$ in shape; product-released nAg were near-spherical $(12-49 \mathrm{~nm})$ or angular $(21-76 \times 29-77 \mathrm{~nm})$ and product-released $\mathrm{nZnO}$ were angular $(32-36 \times 32-40 \mathrm{~nm})$ 
in shape. The ENMs release rate was determined to be $c a 0.4-95 \%$ relative to the initial amount of ENMs added to NEPs. The extent and characteristics of product-released ENMs were influenced by receiving water quality, ENMs loci in the product, and the formulation of the product matrix, while illumination variation essentially did not exert influence. Predominantly, the product-released ENMs were released in association with coating agents ( $\mathrm{Si}$ and $\mathrm{Al}$ ) and ionic forms. Considering the influential role the surface coating exerts on the behaviour and toxicity of ENMs in water resources, we highly recommend the reporting of the presence and characteristics of coating agents on product-released ENMs since it is currently not standard practice.

SUN1, CA1 and SK1 released binary ENMs. Typically, there is currently limited information on the environmental implications of ENMs mixtures, more so for productreleased ENMs; hence, we encourage more studies to unravel the exposure and hazard dynamics of product-released ENMs mixtures.

Nanopollution is an emerging environmental health issue that is yet to be clearly quantified. Nevertheless, proactive mitigation measures can reduce environmental exposure, for instance, the reduction in ENMs quantity in NEPs (safety-by-design principle), since this study demonstrated that the NEPs sample caused nanopollution. In low- and middle-income countries, such as South Africa, where the current study was carried out, there must be accelerated efforts to estimate the size of the NEPs market to refine the extent of nanopollution, as developed regions have advanced in that aspect.

Supplementary Materials: The following are available online at https://www.mdpi.com/article/10 .3390/nano11102537/s1, S1.1 Properties of the release media of SUN1-3, Table S1. Average physicochemical properties of release media before and after ENMs release, Figure S1. The EDX spectra of product-released ENMs obtained under light conditions for SUN1 detected in milli-Q water (A), freshwater (B), swimming pool water (C), seawater (D); SUN2 detected in milli-Q water (E), freshwater $(\mathrm{F})$, swimming pool water $(\mathrm{G})$, seawater $(\mathrm{H})$ and SUN3 detected in milli-Q water (I), freshwater $(\mathrm{J})$, swimming pool water (K), seawater (L), Figure S2. TEM images of product-released ENMs obtained under dark conditions for SUN1 detected in milli-Q water (A), freshwater (B), swimming pool water (C), seawater (D); SUN2 detected in milli-Q water (E), freshwater (F), swimming pool water (G), seawater $(\mathrm{H})$ and SUN3 detected in milli-Q water (I), freshwater (J), swimming pool water $(\mathrm{K})$, seawater (L), Figure S3. Corresponding EDX images of product-released ENMs obtained under dark conditions for SUN1 detected in milli-Q water (A), freshwater (B), swimming pool water (C), seawater (D); SUN2 detected in milli-Q water (E), freshwater $(F)$, swimming pool water $(G)$, seawater $(H)$ and SUN3 detected in milli-Q water (I), freshwater (J), swimming pool water (K), seawater (L), Figure S4. EDX elemental mapping showing adsorption and desorption of ENMs coating agents ( $\mathrm{Si}$ and $\mathrm{Al}$ ) on SUN1-released ENMs, Figure S5. EDX elemental mapping showing adsorption and desorption of ENMs coating agents (Si) on SUN2 (A)- and SUN3 (B)-released ENMs, Figure S6A. Violin plot showing particle distribution of SUN1(A)-, SUN2 (B)-, and SUN3 (C)-released ENMs obtained under light conditions. The upper and lower quartiles are highlighted by a solid line, while the dotted line indicates the median. The denser the violin shape, the higher the number of particle size in that region, Figure S6B. Violin plot showing particle distribution of SUN1(A)-, SUN2 (B)-, and SUN3 (C)-released ENMs obtained under dark conditions. The upper and lower quartiles are highlighted by a solid line, while the dotted line indicates the median. The denser the violin shape, the higher the number of particle size in that region, Figure S7. Zeta potential of SUN1-3-released ENMs obtained under dark conditions in different release media of milli-Q water (MQ), freshwater (FW), swimming pool water (SPW), and seawater (SS), Figure S8. Violin plot showing particle distribution of CA1released ENMs (obtained under light and dark conditions) and SAN1-released ENMs. The upper and lower quartiles are highlighted by a solid line, while the dotted line indicates the median. The denser the violin shape, the higher the number of particle size in that region, Figure S9. TEM-EDX image showing of CA1 product-released nAg and product-released $\mathrm{nTiO}_{2}$ obtained under dark conditions, Figure S10. Violin plot showing particle distribution SK1-released ENMs. The upper and lower quartiles are highlighted by a solid line, while the dotted line indicates the median. The denser the violin shape, the higher the number of particle size in that region, Figure S11. Elemental mapping of binary SK1-released ENMs identified as product-released $\mathrm{nTiO}_{2}$ (yellow) and product-released $\mathrm{nAg}$ (red). The images further show evidence of SK1-released $\mathrm{nTiO}_{2}$ particles partially still coated 
with Si and Al, Figure S12. TEM images showing the thick layer introduced by washing SK1 with sodium dodecyl sulfate release media, Figure S13. EDX elemental mapping illustrating Si desorbed from CA1-released ENMs.

Author Contributions: Conceptualisation, M.T. and R.F.L.; methodology, R.F.L. and M.T.; software, R.F.L.; validation, M.T.; formal analysis, R.F.L.; investigation, R.F.L.; resources, M.T.; data curation, R.F.L.; writing—original draft preparation, R.F.L.; writing—review and editing, R.F.L. and M.T.; visualisation, R.F.L. and M.T.; supervision, M.T.; project administration, M.T.; funding acquisition, M.T. All authors have read and agreed to the published version of the manuscript.

Funding: This research was funded by the South African Department of Science and Technology (DST) under the Nanotechnology Health, Safety and Environment Risk Research Platform (grant number: 0085/2015).

Institutional Review Board Statement: Not applicable.

Informed Consent Statement: Not applicable.

Data Availability Statement: The data presented in this study are available on a reasonable request from the corresponding author.

Acknowledgments: This work was supported by the South African Department of Science and Technology (DST) under the Nanotechnology Health, Safety and Environment Risk Research Platform (grant number: 0085/2015). We further wish to thank Jérôme Rose, Melanie Auffan, and Danielle Slomberg funded by Gov4Nano H2020 European Commission project (grant number: 814401), the SERENADE project (Labex Serenade programme (grant number. ANR-11-LABX-0064), and the "Investissements d'Avenir" programme of the French National Research Agency (ANR) through the A*MIDEX project (grant number: ANR-11-IDEX-0001-02) for hosting and mentoring L.R.F.

Conflicts of Interest: The authors declare no conflict of interest.

\section{References}

1. Foss Hansen, S.; Heggelund, L.R.; Revilla Besora, P.; Mackevica, A.; Boldrin, A.; Baun, A.; Hansen, S.F.; Heggelund, L.R.; Revilla Besora, P.; Mackevica, A.; et al. Nanoproducts-What is actually available to European consumers? Environ. Sci. Nano 2016, 3 , 169-180. [CrossRef]

2. BCC Research Global Nanotechnology Market (by Component and Applications), Funding \& Investment, Patent Analysis and 27 Companies Profile \& Recent Developments-Forecast to 2024. Available online: https://www.bccresearch.com/marketresearch/nanotechnology (accessed on 7 October 2020).

3. Vance, M.E.; Kuiken, T.; Vejerano, E.P.; McGinnis, S.P.; Hochella, M.F.; Rejeski, D.; Hull, M.S.; Hull, M.S.; Hull, D.R.; Rejeski, D.; et al. Nanotechnology in the real world: Redeveloping the nanomaterial consumer products inventory. Beilstein J. Nanotechnol. 2015, 6, 1769-1780. [CrossRef]

4. PEN Inventory Finds Increase in Consumer Products Containing Nanoscale Materials. News Archive. Nanotechnology Project. Available online: http:/ / www.nanotechproject.org/news/archive/9242/ (accessed on 4 June 2019).

5. The Nanodatabase. The Nanodatabase is developed by the DTU Environment, the Danish Ecological Council and Danish Consumer Council. Available online: http:/ / nanodb.dk/en/about-us/ (accessed on 21 July 2017).

6. Moeta, P.J.; Wesley-Smith, J.; Maity, A.; Thwala, M. Nano-enabled products in South Africa and the assessment of environmental exposure potential for engineered nanomaterials. SN Appl. Sci. 2019, 1, 577. [CrossRef]

7. Zhang, Y.; Leu, Y.R.; Aitken, R.J.; Riediker, M. Inventory of engineered nanoparticle-containing consumer products available in the singapore retail market and likelihood of release into the aquatic environment. Int. J. Environ. Res. Public Health 2015, 12, 8717-8743. [CrossRef] [PubMed]

8. Biswas, J.K.; Sarkar, D. Nanopollution in the Aquatic Environment and Ecotoxicity: No Nano Issue! Curr. Pollut. Rep. 2019, 5, 4-7. [CrossRef]

9. Rajkovic, S.; Bornhöft, N.A.; van der Weijden, R.; Nowack, B.; Adam, V. Dynamic probabilistic material flow analysis of engineered nanomaterials in European waste treatment systems. Waste Manag. 2020, 113, 118-131. [CrossRef] [PubMed]

10. Adam, V.; Caballero-Guzman, A.; Nowack, B. Considering the forms of released engineered nanomaterials in probabilistic material flow analysis. Environ. Pollut. 2018, 243, 17-27. [CrossRef]

11. Reed, R.B.; Martin, D.P.; Bednar, A.J.; Montaño, M.D.; Westerhoff, P.; Ranville, J.F. Multi-day diurnal measurements of Ticontaining nanoparticle and organic sunscreen chemical release during recreational use of a natural surface water. Environ. Sci. Nano 2017, 4, 69-77. [CrossRef]

12. Wang, J.; Nabi, M.M.; Mohanty, S.K.; Afrooz, A.N.; Cantando, E.; Aich, N.; Baalousha, M. Detection and quantification of engineered particles in urban runoff. Chemosphere 2020, 248, 126070. [CrossRef] [PubMed] 
13. Slomberg, D.L.; Auffan, M.; Guéniche, N.; Angeletti, B.; Campos, A.; Borschneck, D.; Aguerre-Chariol, O.; Rose, J. Anthropogenic Release and Distribution of Titanium Dioxide Particles in a River Downstream of a Nanomaterial Manufacturer Industrial Site. Front. Environ. Sci. 2020, 8, 76. [CrossRef]

14. Gondikas, A.P.; von der Kammer, F.; Reed, R.B.; Wagner, S.; Ranville, J.F.; Hofmann, T.; Von Der Kammer, F.; Reed, R.B.; Wagner, S.; Ranville, J.F.; et al. Release of $\mathrm{TiO}_{2}$ nanoparticles from sunscreens into surface waters: A one-year survey at the old danube recreational lake. Environ. Sci. Technol. 2014, 48, 5415-5422. [CrossRef] [PubMed]

15. Shi, X.; Li, Z.; Chen, W.; Qiang, L.; Xia, J.; Chen, M.; Zhu, L.; Alvarez, P.J.J. Fate of $\mathrm{TiO}_{2}$ nanoparticles entering sewage treatment plants and bioaccumulation in fish in the receiving streams. NanoImpact 2016, 3-4, 96-103. [CrossRef]

16. Mueller, N.C.; Nowack, B. Exposure Modeling of Engineered Nanoparticles in the Environment. Environ. Sci. Technol. 2008, 42, 63. [CrossRef] [PubMed]

17. Gottschalk, F.; Sonderer, T.; Scholz, R.W.; Nowack, B. Modeled Environmental Concentrations of Engineered Nanomaterials $\left(\mathrm{TiO}_{2}, \mathrm{ZnO}, \mathrm{Ag}, \mathrm{CNT}\right.$, Fullerenes) for Different Regions. Environ. Sci. Technol. 2009, 43, 9216-9222. [CrossRef]

18. Coll, C.; Notter, D.; Gottschalk, F.; Sun, T.; Som, C.; Nowack, B. Probabilistic environmental risk assessment of five nanomaterials (nano- $\mathrm{TiO}_{2}$, nano-Ag, nano-ZnO, CNT, and fullerenes). Nanotoxicology 2016, 10, 436-444. [CrossRef]

19. Musee, N. Simulated environmental risk estimation of engineered nanomaterials: A case of cosmetics in Johannesburg City. Hum. Exp. Toxicol. 2011, 30, 1181-1195. [CrossRef]

20. Sun, T.Y.; Bornhöft, N.A.; Hungerbühler, K.; Nowack, B. Dynamic Probabilistic Modeling of Environmental Emissions of Engineered Nanomaterials. Environ. Sci. Technol. 2016, 50, 4701-4711. [CrossRef]

21. Peters, R.J.B.B.; van Bemmel, G.; Milani, N.B.L.L.; den Hertog, G.C.T.T.; Undas, A.K.; van der Lee, M.; Bouwmeester, H. Detection of nanoparticles in Dutch surface waters. Sci. Total Environ. 2018, 621, 210-218. [CrossRef]

22. Aznar, R.; Barahona, F.; Geiss, O.; Ponti, J.; Luis, T.J.; Barrero-Moreno, J. Quantification and size characterisation of silver nanoparticles in environmental aqueous samples and consumer products by single particleICPMS. Talanta 2017, 175, 200-208. [CrossRef]

23. Li, L.; Stoiber, M.; Wimmer, A.; Xu, Z.; Lindenblatt, C.; Helmreich, B.; Schuster, M. To What Extent Can Full-Scale Wastewater Treatment Plant Effluent Influence the Occurrence of Silver-Based Nanoparticles in Surface Waters? Environ. Sci. Technol. 2016, 50, 6327-6333. [CrossRef] [PubMed]

24. Venkatesan, A.K.; Reed, R.B.; Lee, S.; Bi, X.; Hanigan, D.; Yang, Y.; Ranville, J.F.; Herckes, P.; Westerhoff, P. Detection and Sizing of Ti-Containing Particles in Recreational Waters Using Single Particle ICP-MS. Bull. Environ. Contam. Toxicol. 2018, 100, 120-126. [CrossRef]

25. Wu, S.; Zhang, S.; Gong, Y.; Shi, L.; Zhou, B. Identification and quantification of titanium nanoparticles in surface water: A case study in Lake Taihu, China. J. Hazard. Mater. 2020, 382, 121045. [CrossRef]

26. Loosli, F.; Wang, J.; Rothenberg, S.; Bizimis, M.; Winkler, C.; Borovinskaya, O.; Flamigni, L.; Baalousha, M. Sewage spills are a major source of titanium dioxide engineered (nano)-particle release into the environment. Environ. Sci. Nano 2019, 6, 763-777. [CrossRef]

27. Garner, K.L.; Suh, S.; Keller, A.A. Assessing the Risk of Engineered Nanomaterials in the Environment: Development and Application of the nanoFate Model. Environ. Sci. Technol. 2017, 51, 5541-5551. [CrossRef]

28. Lehutso, R.F.; Tancu, Y.; Maity, A.; Thwala, M. Aquatic toxicity of transformed and product-released engineered nanomaterials: An overview of the current state of knowledge. Process Saf. Environ. Prot. 2020, 138, 39-56. [CrossRef]

29. Mitrano, D.M.; Motellier, S.; Clavaguera, S.; Nowack, B. Review of nanomaterial aging and transformations through the life cycle of nano-enhanced products. Environ. Int. 2015, 77, 132-147. [CrossRef] [PubMed]

30. Mitrano, D.M.; Nowack, B. The need for a life-cycle based aging paradigm for nanomaterials: Importance of real-world test systems to identify realistic particle transformations. Nanotechnology 2017, 28, 072001. [CrossRef]

31. Auffan, M.; Pedeutour, M.; Rose, J.; Masion, A.; Ziarelli, F.; Borschneck, D.; Chaneac, C.; Botta, C.; Chaurand, P.; Labille, J.; et al. Structural degradation at the surface of $\mathrm{a} \mathrm{TiO}_{2}$-based nanomaterial used in cosmetics. Environ. Sci. Technol. 2010, 44, 2689-2694. [CrossRef] [PubMed]

32. Mitrano, D.M.; Lombi, E.; Dasilva, Y.A.R.; Nowack, B.; Arroyo, Y.; Dasilva, R.; Nowack, B. Unraveling the Complexity in the Aging of Nanoenhanced Textiles: A Comprehensive Sequential Study on the Effects of Sunlight and Washing on Silver Nanoparticles. Environ. Sci. Technol. 2016, 50, 5790-5799. [CrossRef] [PubMed]

33. Gagnon, V.; Button, M.; Boparai, H.K.; Nearing, M.; O'Carroll, D.M.; Weber, K.P.; Nearing, M.; Weber, K.P.; Boparai, H.K.; Button, M.; et al. Influence of realistic wearing on the morphology and release of silver nanomaterials from textiles. Environ. Sci. Nano 2018, 6, 411-424. [CrossRef]

34. Lorenz, C.; Windler, L.; von Goetz, N.; Lehmann, R.P.P.; Schuppler, M.; Hungerbühler, K.; Heuberger, M.; Nowack, B. Characterization of silver release from commercially available functional (nano)textiles. Chemosphere 2012, 89, 817-824. [CrossRef]

35. Lombi, E.; Donner, E.; Scheckel, K.G.; Sekine, R.; Lorenz, C.; Von Goetz, N.; Nowack, B. Silver speciation and release in commercial antimicrobial textiles as influenced by washing. Chemosphere 2014, 111, 352-358. [CrossRef]

36. Koivisto, A.J.; Jensen, A.C.Ø.; Kling, K.I.; Nørgaard, A.; Brinch, A.; Christensen, F.; Jensen, K.A. Quantitative material releases from products and articles containing manufactured nanomaterials: Towards a release library. NanoImpact 2017, 5, 119-132. [CrossRef] 
37. Nowack, B.; Mitrano, D.M. Procedures for the production and use of synthetically aged and product released nanomaterials for further environmental and ecotoxicity testing. NanoImpact 2018, 10, 70-80. [CrossRef]

38. Hristozov, D.R.; Gottardo, S.; Critto, A.; Marcomini, A. Risk assessment of engineered nanomaterials: A review of available data and approaches from a regulatory perspective. Nanotoxicology 2012, 6, 880-898. [CrossRef] [PubMed]

39. Jacobs, R.; Meesters, J.A.J.; ter Braak, C.J.F.; van de Meent, D.; van der Voet, H. Combining exposure and effect modeling into an integrated probabilistic environmental risk assessment for nanoparticles. Environ. Toxicol. Chem. 2016, 35, 2958-2967. [CrossRef]

40. Salieri, B.; Turner, D.A.; Nowack, B.; Hischier, R. Life cycle assessment of manufactured nanomaterials: Where are we? NanoImpact 2018, 10, 108-120. [CrossRef]

41. Lehutso, R.F.; Tancu, Y.; Maity, A.; Thwala, M. Molecules Characterisation of Engineered Nanomaterials in Nano-Enabled Products Exhibiting Priority Environmental Exposure. Molecules 2020, 26, 1370. [CrossRef]

42. Nthwane, Y.B.; Tancu, Y.; Maity, A.; Thwala, M. Characterisation of titanium oxide nanomaterials in sunscreens obtained by extraction and release exposure scenarios. SN Appl. Sci. 2019, 1, 312. [CrossRef]

43. Botta, C.; Labille, J.; Auffan, M.; Borschneck, D.; Miche, H.H.; Cabié, M.; Masion, A.; Rose, J.; Bottero, J.-Y.Y. TiOㄱ-based nanoparticles released in water from commercialized sunscreens in a life-cycle perspective: Structures and quantities. Environ. Pollut. 2011, 159, 1543-1550. [CrossRef]

44. Limpiteeprakan, P.; Babel, S.; Lohwacharin, J.; Takizawa, S. Release of silver nanoparticles from fabrics during the course of sequential washing. Environ. Sci. Pollut. Res. 2016, 23, 22810-22818. [CrossRef] [PubMed]

45. Mitrano, D.M.; Arroyo Rojas Dasilva, Y.; Nowack, B. Effect of Variations of Washing Solution Chemistry on Nanomaterial Physicochemical Changes in the Laundry Cycle. Environ. Sci. Technol. 2015, 49, 9665-9673. [CrossRef] [PubMed]

46. Benn, T.; Cavanagh, B.; Hristovski, K.; Posner, J.D.; Westerhoff, P. The Release of Nanosilver from Consumer Products Used in the Home. J. Environ. Qual. 2010, 39, 1875. [CrossRef] [PubMed]

47. Mackevica, A.; Olsson, M.E.; Hansen, S.F. The release of silver nanoparticles from commercial toothbrushes. J. Hazard. Mater. 2017, 322, 270-275. [CrossRef]

48. CEM MARS Microwave Digestion-Sample Preparation using Microwave Digestion. Available online: http://cem.com/ microwave-digestion (accessed on 16 July 2018).

49. Lewicka, Z.A.; Benedetto, A.F.; Benoit, D.N.; Yu, W.W.; Fortner, J.D.; Colvin, V.L. The structure, composition, and dimensions of $\mathrm{TiO}_{2}$ and $\mathrm{ZnO}$ nanomaterials in commercial sunscreens. J. Nanopart. Res. 2011, 13, 3607-3617. [CrossRef]

50. Philippe, A.; Košík, J.; Welle, A.; Guigner, J.-M.; Clemens, O.; Schaumann, G.E. Extraction and characterization methods for titanium dioxide nanoparticles from commercialized sunscreens. Environ. Sci. Nano 2018, 5, 191-202. [CrossRef]

51. Lu, P.-J.J.; Huang, S.-C.C.; Chen, Y.-P.P.; Chiueh, L.-C.C.; Shih, D.Y.-C.C. Analysis of titanium dioxide and zinc oxide nanoparticles in cosmetics. J. Food Drug Anal. 2015, 23, 587-594. [CrossRef]

52. Al-Abed, S.R.; Virkutyte, J.; Ortenzio, J.N.R.; McCarrick, R.M.; Degn, L.L.; Zucker, R.; Coates, N.H.; Childs, K.; Ma, H.; Diamond, S.; et al. Environmental aging alters $\mathrm{Al}(\mathrm{OH})_{3}$ coating of $\mathrm{TiO}_{2}$ nanoparticles enhancing their photocatalytic and phototoxic activities. Environ. Sci. Nano 2016, 3, 593-601. [CrossRef]

53. Camilleri, C.; Markich, S.J.; Noller, B.N.; Turley, C.J.; Parker, G.; Van Dam, R.A. Silica reduces the toxicity of aluminium to a tropical freshwater fish (Mogurnda mogurnda). Chemosphere 2003, 50, 355-364. [CrossRef]

54. Nnamdi, A.H.; Briggs, T.M.D.; Togunde, O.O.; Obanya, H.E. Antagonistic effects of sublethal concentrations of certain mixtures of metal oxide nanoparticles and the bulk $\left(\mathrm{Al}_{2} \mathrm{O}_{3}, \mathrm{CuO}\right.$, and $\left.\mathrm{SiO}_{2}\right)$ on gill histology in clarias gariepinus. J. Nanotechnol. 2019, 2019, 7686597. [CrossRef]

55. Ríos, F.; Fernández-Arteaga, A.; Fernández-Serrano, M.; Jurado, E.; Lechuga, M. Silica micro- and nanoparticles reduce the toxicity of surfactant solutions. J. Hazard. Mater. 2018, 353, 436-443. [CrossRef]

56. Choudhary, R.; Khurana, D.; Kumar, A.; Subudhi, S. Stability analysis of $\mathrm{Al}_{2} \mathrm{O}_{3}$ / water nanofluids. J. Exp. Nanosci. 2017, 12, 140-151. [CrossRef]

57. Negm, N.A.; Tawfik, S.M.; Abd-Elaal, A.A. Synthesis, characterization and biological activity of colloidal silver nanoparticles stabilized by gemini anionic surfactants. J. Ind. Eng. Chem. 2015, 21, 1051-1057. [CrossRef]

58. Shao, X.-R.; Wei, X.-Q.; Song, X.; Hao, L.-Y.; Cai, X.-X.; Zhang, Z.-R.; Peng, Q.; Lin, Y.-F. Independent effect of polymeric nanoparticle zeta potential/surface charge, on their cytotoxicity and affinity to cells. Cell Prolif. 2015, 48, 465-474. [CrossRef] [PubMed]

59. Zhu, Z.J.; Wang, H.; Yan, B.; Zheng, H.; Jiang, Y.; Miranda, O.R.; Rotello, V.M.; Xing, B.; Vachet, R.W. Effect of surface charge on the uptake and distribution of gold nanoparticles in four plant species. Environ. Sci. Technol. 2012, 46, 12391-12398. [CrossRef]

60. Jeon, S.; Kim, E.; Lee, J.; Lee, S. Potential risks of $\mathrm{TiO}_{2}$ and $\mathrm{ZnO}$ nanoparticles released from sunscreens into outdoor swimming pools. J. Hazard. Mater. 2016, 317, 312-318. [CrossRef]

61. Levard, C.; Hotze, E.M.; Lowry, G.V.; Brown, G.E. Environmental transformations of silver nanoparticles: Impact on stability and toxicity. Environ. Sci. Technol. 2012, 46, 6900-6914. [CrossRef]

62. Lowry, G.V.; Gregory, K.B.; Apte, S.C.; Lead, J.R. Transformations of Nanomaterials in the Environment. Environ. Sci. Technol. 2012, 46, 6893-6899. [CrossRef]

63. Zhang, W.; Xiao, B.; Fang, T. Chemical transformation of silver nanoparticles in aquatic environments: Mechanism, morphology and toxicity. Chemosphere 2018, 191, 324-334. [CrossRef] 
64. Peretyazhko, T.S.; Zhang, Q.; Colvin, V.L. Size-controlled dissolution of silver nanoparticles at neutral and acidic $\mathrm{pH}$ conditions: Kinetics and size changes. Environ. Sci. Technol. 2014, 48, 11954-11961. [CrossRef]

65. Yu, S.; Yin, Y.; Chao, J.; Shen, M.; Liu, J. Highly Dynamic PVP-Coated Silver Nanoparticles in Aquatic Environments: Chemical and Morphology Change Induced by Oxidation of $\mathrm{Ag}^{0}$ and Reduction of $\mathrm{Ag}^{+}$. Environ. Sci. Technol. 2014, 48, 403-411. [CrossRef]

66. Hou, W.C.; Stuart, B.; Howes, R.; Zepp, R.G. Sunlight-driven reduction of silver ions by natural organic matter: Formation and transformation of silver nanoparticles. Environ. Sci. Technol. 2013, 47, 7713-7721. [CrossRef]

67. Radwan, I.M.; Gitipour, A.; Potter, P.M.; Dionysiou, D.D.; Al-Abed, S.R. Dissolution of silver nanoparticles in colloidal consumer products: Effects of particle size and capping agent. J. Nanopart. Res. 2019, 21, 155. [CrossRef]

68. Wan, J.; Kim, Y.; Mulvihill, M.J.; Tokunaga, T.K. Dilution destabilizes engineered ligand-coated nanoparticles in aqueous suspensions. Environ. Toxicol. Chem. 2018, 37, 1301-1308. [CrossRef] [PubMed]

69. Hedberg, J.; Eriksson, M.; Kesraoui, A.; Norén, A.; Odnevall Wallinder, I. Transformation of silver nanoparticles released from skin cream and mouth spray in artificial sweat and saliva solutions: Particle size, dissolution, and surface area. Environ. Sci. Pollut. Res. 2020, 28, 12968-12979. [CrossRef] [PubMed]

70. Mitrano, D.M.; Rimmele, E.; Wichser, A.; Erni, R.; Height, M.; Nowack, B. Presence of nanoparticles in wash water from conventional silver and nano-silver textiles. ACS Nano 2014, 8, 7208-7219. [CrossRef] [PubMed]

71. Windler, L.; Lorenz, C.; Von Goetz, N.; Hungerbühler, K.; Amberg, M.; Heuberger, M.; Nowack, B. Release of titanium dioxide from textiles during washing. Environ. Sci. Technol. 2012, 46, 8181-8188. [CrossRef] [PubMed]

72. Kaegi, R.; Sinnet, B.; Zuleeg, S.; Hagendorfer, H.; Mueller, E.; Vonbank, R.; Boller, M.; Burkhardt, M. Release of silver nanoparticles from outdoor facades. Environ. Pollut. 2010, 158, 2900-2905. [CrossRef]

73. Labille, J.; Slomberg, D.; Catalano, R.; Robert, S.; Apers-Tremelo, M.L.; Boudenne, J.L.; Manasfi, T.; Radakovitch, O. Assessing UV filter inputs into beach waters during recreational activity: A field study of three French Mediterranean beaches from consumer survey to water analysis. Sci. Total Environ. 2020, 706, 136010. [CrossRef]

74. Gondikas, A.; Von Der Kammer, F.; Kaegi, R.; Borovinskaya, O.; Neubauer, E.; Navratilova, J.; Praetorius, A.; Cornelis, G.; Hofmann, T. Where is the nano? Analytical approaches for the detection and quantification of $\mathrm{TiO}_{2}$ engineered nanoparticles in surface waters. Environ. Sci. Nano 2018, 5, 313-326. [CrossRef]

75. Sanchís, J.; Jiménez-Lamana, J.; Abad, E.; Szpunar, J.; Farré, M. Occurrence of Cerium-, Titanium-, and Silver-Bearing Nanoparticles in the Besòs and Ebro Rivers. Environ. Sci. Technol. 2020, 54, 3969-3978. [CrossRef]

76. Rouhnia, M.; Strom, K. Sedimentation from flocculated suspensions in the presence of settling-driven gravitational interface instabilities. J. Geophys. Res. Ocean. 2015, 120, 6384-6404. [CrossRef]

77. Liu, Y.; Nie, Y.; Wang, J.; Wang, J.; Wang, X.; Chen, S.; Zhao, G.; Wu, L.; Xu, A. Mechanisms involved in the impact of engineered nanomaterials on the joint toxicity with environmental pollutants. Ecotoxicol. Environ. Saf. 2018, 162, 92-102. [CrossRef]

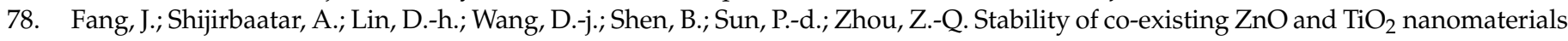
in natural water: Aggregation and sedimentation mechanisms. Chemosphere 2017, 184, 1125-1133. [CrossRef] [PubMed]

79. Foss Hansen, S.; Larsen, B.H.; Olsen, S.I.; Baun, A. Categorization framework to aid hazard identification of nanomaterials. Nanotoxicology 2007, 1, 243-250. [CrossRef]

80. Quadros, M.; Pierson, R.I.; Tulve, N.; Willis, R.; Rogers, K.; Thomas, T.; Marr, L.C. Release of Silver from Nanotechnology-Based Consumer Products for Children. Environ. Sci. Technol. 2013, 47, 8894-8901. [CrossRef] [PubMed]

81. Ale, A.; Liberatori, G.; Vannuccini, M.L.; Bergami, E.; Ancora, S.; Mariotti, G.; Bianchi, N.; Galdopórpora, J.M.; Desimone, M.F.; Cazenave, J.; et al. Exposure to a nanosilver-enabled consumer product results in similar accumulation and toxicity of silver nanoparticles in the marine mussel Mytilus galloprovincialis. Aquat. Toxicol. 2019, 211, 46-56. [CrossRef] [PubMed]

82. Hedberg, J.; Skoglund, S.; Karlsson, M.-E.E.; Wold, S.; Odnevall Wallinder, I.; Hedberg, Y. Sequential studies of silver released from silver nanoparticles in aqueous media simulating sweat, laundry detergent solutions and surface water. Environ. Sci. Technol. 2014, 48, 7314-7322. [CrossRef]

83. Mitrano, D.M.; Ranville, J.F.; Bednar, A.; Kazor, K.; Hering, A.S.; Higgins, C.P. Tracking dissolution of silver nanoparticles at environmentally relevant concentrations in laboratory, natural, and processed waters using single particle ICP-MS (spICP-MS). Environ. Sci. Nano 2014, 1, 248-259. [CrossRef]

84. Liu, C.; Leng, W.; Vikesland, P.J. Controlled Evaluation of the Impacts of Surface Coatings on Silver Nanoparticle Dissolution Rates. Environ. Sci. Technol. 2018, 52, 2726-2734. [CrossRef]

85. Jiménez-Lamana, J.; Slaveykova, V.I. Silver nanoparticle behaviour in lake water depends on their surface coating. Sci. Total Environ. 2016, 573, 946-953. [CrossRef] [PubMed]

86. Ma, R.; Levard, C.; Marinakos, S.M.; Cheng, Y.; Liu, J.; Michel, F.M.; Brown, G.E.; Lowry, G.V. Size-controlled dissolution of organic-coated silver nanoparticles. Environ. Sci. Technol. 2012, 46, 752-759. [CrossRef] [PubMed]

87. Borm, P.; Klaessig, F.C.; Landry, T.D.; Moudgil, B.; Pauluhn, J.; Thomas, K.; Trottier, R.; Wood, S. Research strategies for safety evaluation of nanomaterials, Part V: Role of dissolution in biological fate and effects of nanoscale particles. Toxicol. Sci. 2006, 90, 23-32. [CrossRef] [PubMed]

88. Hedberg, J.; Blomberg, E.; Odnevall Wallinder, I. In the Search for Nanospecific Effects of Dissolution of Metallic Nanoparticles at Freshwater-Like Conditions: A Critical Review. Environ. Sci. Technol. 2019, 53, 4030-4044. [CrossRef] [PubMed] 
89. De Leersnyder, I.; Rijckaert, H.; De Gelder, L.; Van Driessche, I.; Vermeir, P. High Variability in Silver Particle Characteristics, Silver Concentrations, and Production Batches of Commercially Available Products Indicates the Need for a More Rigorous Approach. Nanomaterials 2020, 10, 1394. [CrossRef] [PubMed]

90. Geranio, L.; Heuberger, M.; Nowack, B. The Behavior of Silver Nanotextiles during Washing. Environ. Sci. Technol. 2009, 43, 8113-8118. [CrossRef] [PubMed]

91. Kim, J.B.; Kim, J.Y.; Yoon, T.H. Determination of silver nanoparticle species released from textiles into artificial sweat and laundry wash for a risk assessment. Hum. Ecol. Risk Assess. Int. J. 2017, 23, 741-750. [CrossRef]

92. Mackevica, A.; Olsson, M.E.; Hansen, S.F. Quantitative characterization of $\mathrm{TiO}_{2}$ nanoparticle release from textiles by conventional and single particle ICP-MS. J. Nanopart. Res. 2018, 20, 6. [CrossRef]

93. Benn, T.M.; Westerhoff, P. Nanoparticle Silver Released into Water from Commercially Available Sock Fabrics. Environ. Sci. Technol. 2008, 42, 4133-4139. [CrossRef]

94. Baek, S.; Joo, S.H.; Blackwelder, P.; Toborek, M. Effects of coating materials on antibacterial properties of industrial and sunscreenderived titanium-dioxide nanoparticles on Escherichia coli. Chemosphere 2018, 208, 196-206. [CrossRef]

95. Virkutyte, J.; Al-Abed, S.R.; Dionysiou, D.D.; Chen, Y.; Capco, D.D.G.D.; Capco, D.D.G.D. Depletion of the protective aluminum hydroxide coating in $\mathrm{TiO}_{2}$-based sunscreens by swimming pool water ingredients. Chem. Eng. J. 2012, 191, 95-103. [CrossRef]

96. Labille, J.; Feng, J.; Botta, C.; Borschneck, D.; Sammut, M.; Cabie, M.; Auffan, M.; Rose, J.; Bottero, J.-Y. Aging of TiO 2 nanocomposites used in sunscreen. Dispersion and fate of the degradation products in aqueous environment. Environ. Pollut. 2010, 158, 3482-3489. [CrossRef]

97. Slomberg, D.L.; Catalano, R.; Ziarelli, F.; Viel, S.; Bartolomei, V.; Labille, J.; Masion, A. Aqueous aging of a silica coated TiO 2 UV filter used in sunscreens: Investigations at the molecular scale with dynamic nuclear polarization NMR. RSC Adv. 2020, 10, 8266-8274. [CrossRef] 